\title{
Perceived Cultural Impacts of Climate Change Motivates Climate Action and Support for Climate Policy
}

\author{
Kim-Pong Tam \\ The Hong Kong University of Science and Technology \\ Angela K.-y. Leung \\ Singapore Management University \\ Brandon Koh \\ Singapore University of Social Sciences
}

This is a pre-print of a manuscript that is now published in Climatic Change. Visit https://doi.org/10.1007/s10584-022-03337-8 for the published article.

Correspondence:

Correspondence concerning this article should be addressed to Kim-Pong Tam, Division of Social Science, The Hong Kong University of Science and Technology, Clear Water Bay, Hong Kong; phone: +852 23587828; e-mail: kevintam@ust.hk.

Acknowledgement:

The work described in this study was partially supported by a grant from the Research Grants Council of the Hong Kong Special Administrative Region, China (Project No. 16602119). 


\begin{abstract}
The impacts of climate change on human cultures receive increasing attention in recent years. However, the extent to which people are aware of these impacts, whether such awareness motivates climate action, and what kinds of people show stronger awareness are rarely understood. The present investigation provides the very first set of answers to these questions. In two studies (with a student sample with $N=198$ from Singapore and a demographically representative sample with $N=571$ from the United States), we observed a generally high level of awareness among our participants. Most important, perceived cultural impacts of climate change robustly predicted intentions to engage in climate change mitigation behavior and climate activism, as well as support for climate policy. We also found expected associations between perceived cultural impacts and psychological and demographic variables (e.g., cosmopolitan orientation, moral inclusion, political orientation). These findings not only add a cultural dimension to the research on public understanding of climate change but also reveal a viable application of cultural frames as an effective climate communication strategy.
\end{abstract}

Keywords: climate change; culture; perceived impact; mitigation behavior; climate activism; climate policy 
It was Rio 2016 Summer Olympics. David Katoatau, a weightlifter from the Pacific nation of Kiribati, danced on the stage after his event. He danced not because he had won the competition; he finished sixth. He danced because he wanted to raise awareness of the threat posed by climate change to his compatriots and his culture. In an open letter, he wrote: “On behalf of all the people who will die for the country that will no longer exist and for the culture which will long be forgotten, I am asking for your help” (Katoatau, n.d.).

With the environmental changes (e.g., extreme weather events, sea level rise) it brings, climate change threatens not only physical and biological systems but also human systems (IPCC, 2014). The impacts on human systems are usually understood in terms of health crises, economy losses, or risk of conflicts. Recently, the impacts of climate change on human cultures receive increasing attention (Fatorić \& Seekamp, 2017). Culture refers to both tangible (e.g., monuments, historical sites) and intangible entities (e.g., values, language, know-hows, traditions) that have shared meanings in a community (UNESCO, 2001). Few cultures can escape the impacts of climate change, whether they are in the developed world or marginal societies (Adger et al., 2013). In extreme cases (e.g., Kiribati), an entire community will disappear, and its culture is on the edge of extinction (Weiss, 2015).

Despite the evidenced cultural impacts of climate change, how the public perceive and respond to these impacts is rarely understood. To what extent do the public perceive the cultural impacts of climate change? What kinds of individuals are more aware of such impacts? To what extent does perception of the threat of climate change to cultural sustainability motivate engagement in climate action? The present investigation sets out to address these questions.

\section{Cultural Impacts of Climate Change}

Climate change threatens human cultures in diverse ways. It can cause damages to tangible cultural heritage (Anderson et al., 2017). The Union of Concerned Scientists released 
a report detailing how rising sea levels and intense and frequent floods and wildfires, associated with a changing climate, are already threatening iconic and historic sites in the United States (Holtz et al., 2014). For example, Hurricane Sandy submerged most of Liberty and Ellis islands in 2014, causing destruction that took months and millions of dollars to recover. Globally, it is estimated that even if the current global temperature remains unchanged for the coming two millennia, about $6.5 \%$ of UNESCO cultural heritage sites will still be submerged below sea level (Marzeion \& Levermann, 2014). This numbers can go up to $20 \%$ if global temperature continues to rise. The UNESCO World Heritage Center (2007) also identified climate change as one of the most serious threats to the conservation of cultural heritage. Their study in 2005 revealed that 46 world heritage sites had been experiencing impacts of climate change. Among the various threats, hurricanes, sea level rise, erosion, and floods were most frequently cited. An example is Timbuktu in Mali, once a center for the propagation of Islam in Africa in the $15^{\text {th }}$ to $16^{\text {th }}$ centuries. Extreme rainfalls in early 2000 s caused collapse of traditional buildings; in other years, severe droughts enhanced desert encroachment and hence sand-blown damage to the structures.

Attention should also be paid to the intangible aspects of cultures. Because communities are rooted in places, when geophysical impacts of climate change affect an area, the communities there and their cultures will be affected. An example is Niue, a Polynesian island (Adger et al., 2013). The island has been exposed to cyclones, which in recent years have taken away many subsistence resources (e.g., tree stocks for making canoes, which support fishing practices) and culturally significant places (e.g., national museums). Coupled with population decline, Niuean culture is now facing survival challenges. Numerous cases of intangible cultural threats can be found among indigenous communities. For example, prolonged drought caused habitat and wildlife loss, limiting pastoralists’ access to the natural resources they once had enjoyed and thereby contributing to a diminution of the traditional 
men's roles and the practices shared in the community (Rigby et al., 2011). Some participants pointed out that these impacts compromise people's well-being and promoted antisocial behavior, bringing shame and distrust to the Aboriginal culture. As recognized by the United Nations (2009): “...indigenous peoples are the ones most at risk from the consequences of climate change because of their dependence upon and close relationship with the environment and its resources... Indigenous communities already affected by other stresses (such as, for example, the aftermath of resettlement processes) are considered especially vulnerable” (p. 96).

\section{Perceived Cultural Impacts of Climate Change: A Research Gap}

As reviewed, climate change threatens human cultures. However, little research has considered how the public understands this cultural threat by climate change. With respect to how people understand climate change impacts, three lines of research can be identified. As explained below, the cultural dimension has been missing in all of them.

The first line of research involves studies wherein researchers directly ask respondents about their understanding of climate change impacts. In some studies, the questions referred to overall impacts. For instance, in the Six Americas Surveys (Maibach et al., 2011), questions regarding perceived harm of global warming to different parties (e.g., self, future generations, people in the country) were included. In some other studies, a domain was specified, but culture was not considered. Health was the most widely explored domain. In a review of previous studies, Hathaway and Maibach (2018) observed that most people from developed countries knew little about how climate change was relevant to health, but they believed that climate change was harmful to health. Another domain that attracted attention is economy. For example, the public in Bangladesh are highly aware of the threat of climate change to the local economy (Haque et al., 2012).

The second line of research examines people's perception of the co-benefits of climate 
change mitigation. Respondents were asked to report their projections about the future of society, in comparison to today, if climate change is successfully mitigated. In a 24-country study (Bain et al., 2016), it was observed that individuals recognized the benefits of climate change mitigation to different extents along two major dimensions: societal development (e.g., economic development, scientific progress) and reduction of dysfunction (e.g., violent crime, disease). These findings suggest that some people perceive that mitigating climate change can improve society, hinting that they do recognize the societal impacts of climate change. In these studies, the types of co-benefits covered did not include the cultural dimension.

The third line of research compares the effectiveness of different message frames in climate change communication. Traditionally, climate change has been framed as an environmental issue (Wibeck, 2014). This frame presents scientific facts about climate change, focusing on the environmental changes it brings, its impacts on ecosystems, and the benefits of its mitigation for ecosystems. Not surprisingly, given the prevalence of this frame, the public tends to understand climate change as an environmental problem (Maibach et al., 2010). However, it has been suggested that the environmental frame is ineffective, as it relegates climate change to an issue "where animals and habitats are affected rather than humans” (Doyle, 2007, p.142). In recent studies, alternative non-environmental frames have been considered (e.g., Maibach et al., 2010). These frames highlight the impacts of climate change on human systems (e.g., health, national security) and make more salient the human benefits of climate change mitigation. Generally, these frames are able to elicit stronger concern for climate change and support for its mitigation (Moser, 2010). Although these studies did not directly examine how the public perceive climate change impacts, they are relevant because they consider how the public respond when the impacts of climate change are brought to attention. To the best of our knowledge, no study has ever examined how the 
public respond to a message that emphasizes the cultural impacts of climate change.

In sum, we can conclude that little, if any, is known as to whether the public are aware of the cultural impacts of climate change and how they respond to these impacts. We thus address this issue in the present research by answering three questions: 1) To what extent do members of the public perceive the cultural impacts of climate change? 2) To what extent do such perceptions motivate engagement in climate change mitigation? 3) What characterizes those individuals who are more aware of the cultural impacts of climate change? Next, we detail our hypotheses with respect to these three questions.

\section{Hypotheses}

\subsection{Prevalence of Perceived Cultural Impacts of Climate Change}

Considering the paucity of research on public understanding of the cultural implications of climate change, it appears difficult to draw a concrete hypothesis regarding the prevalence of perceived cultural impacts. That said, recent public polls consistently revealed that the public worldwide shows considerable awareness of the general impacts of climate change. According to a recent survey conducted by the Pew Research Center, in half of the countries surveyed, the public named climate change as the top international threat (Poushter \& Huang, February 10, 2019). Another poll by YouGov covering 28 countries revealed that across the world people generally expected climate change to have moderate to large impacts on their living (Smith, September 15, 2019). In all countries, over half of the respondents thought climate change would likely cause serious damage to the global economy, loss of cities, mass displacement of people, and even wars. Taking these recent trends into account, we expect that our respondents on average would show a high level of awareness of the cultural impacts of climate change.

\subsection{Perceived Cultural Impacts and Climate Action}

A commonly cited psychological barrier to climate action is psychological distance 
(McDonald et al., 2015). Climate change is seen by some to have influences in the future, be full of uncertainties, affect other people more than the self, and have impacts elsewhere. Evidence suggests that when individuals experience more psychological distance from climate change, they are less concerned about it and less prepared to take action to address it (e.g., Spence et al., 2012).

Perceiving the impacts of climate change on different aspects of human systems suggest that climate change is a more personally relevant concern, and its mitigation bears personal benefits (McDonald et al., 2015; Spence et al., 2012). We thus hypothesize that perceiving cultural impacts of climate change can reduce its psychological distance and thereby motivate engagement in climate action, as culture is an important part of the human systems and has direct relevance to people’s everyday living. Research findings from the three lines of research reviewed earlier hint at the validity of this hypothesis. First, people who perceive more human-related impacts tend to engage in more climate action. For example, individuals who perceived more threat of climate change to health and well-being reported stronger support for mitigation policy and sustainable lifestyles (DeBono et al., 2012). Second, studies showed that people who perceive more co-benefits of climate change mitigation exhibit stronger intention to perform climate action (e.g., Bain et al., 2016). Third, climate change communication studies revealed that messages with human-related frames can effectively elicit concern for climate change and support for its mitigation (e.g., Maibach et al., 2010).

In all, people tend to respond to climate change more positively when they are aware of its relevance to human systems. We therefore expect that individuals with higher levels of perceive cultural impacts of climate change exhibit more climate change engagement.

\subsection{Individual Differences in Perceived Cultural Impacts}

Next, we consider what kinds of individuals are more likely to recognize the cultural impacts of climate change. 
We first consider some psychological factors. The first is cosmopolitan orientation, which refers to the attitudinal and value orientations of individuals who immerse as part of the globalized world (Leung et al., 2015). Cosmopolitan individuals are interested in and concerned about human cultures, both local and foreign. They exhibit tolerance and appreciation for cultural differences, receptiveness to immerse in and learn from other cultures, and empathy and protectiveness with others regardless of their cultural backgrounds (Liu et al., 2020). Findings show that individuals with high cosmopolitan orientation exhibit stronger concern about environmental issues, intention to perform pro-environmental behavior, and support for the environmental movement (Leung et al., 2015). It is conceivable that these individuals are more sensitive to various kinds of threat to human cultures, including that of climate change. For the same reasoning, we expect that individuals with strong ethnocentrism, who tend to perceive their own group as superior and the centre of everything and to distain outgroups (Bizumic \& Duckitt, 2012), to be less aware of the cultural impacts of climate change, at least those on foreign soil.

The above hypotheses can also be interpreted through the notion of moral inclusion or expansiveness (Opotow \& Weiss, 2000). The cultural impacts of climate change are global; they do not necessarily happen domestically. Some of these impacts happen to remote countries and are experienced most strongly by marginal populations (Adger et al., 2013). We expect that individuals who have a wider span of moral regard would be more sensitive to information regarding the cultural impacts of climate change, whether they happen locally or elsewhere. We operationalize moral inclusion with two concepts: identification with all humanity (McFarland et al., 2012), which refers to the tendency to feel kinship and connection to all humans, and the value of universalism (Schwartz, 1992), which stands for "understanding, appreciation, tolerance and protection for the welfare of all people and for nature” (p.12). Both concepts have been found to predict general humanitarian concerns and 
engagement in climate change (e.g., McFarland et al., 2012).

Political orientation is a strong factor underlying the diversity of climate change opinion (Hornsey et al., 2016) and concern with environmental issues (Cruz, 2017). Politically left or liberal individuals tend to be more concerned about climate change than politically right or conservative individuals. The magnitude of this political divide varies across countries and tend to be stronger in the United States and Western societies (Hornsey et al., 2018). This political gap is also observed in people's perceptions of climate change impacts. For example, in the United States, whereas 81\% of Democrats think that climate change will harm people in the country, only 38\% of Republicans think so (Mildenberger et al., 2017). Accordingly, we hypothesize that individuals with a conservative (vs. liberal) orientation and Republicans (vs. Democrats) in the United States are less likely to recognize the cultural impacts of climate change.

We also consider age, gender, education, income, and ethnicity. Among these demographic factors, we speculate that education is likely to be associated with perceived cultural impacts, as more educated individuals should have more access to and understanding of information regarding climate change (Hornsey et al., 2018). We also expect a strong relationship between perceived cultural impacts and general climate change opinions (including belief in anthropogenic causes, belief in scientific consensus, perceived harm to self, and perceived harm to the country). That is, people with more pro-climate views are hypothesized to be more aware of the cultural impacts of climate change.

\section{The Present Research}

To support our investigation, we need a measure that can capture people’s perceived cultural impacts of climate change. We adopt the psychometric approach (Deville, 2003) to develop this measure in Study 1. With this measure, we tested our hypotheses in two studies. Study 1 recruited a student sample in Singapore. Study 2 was a preregistered study and 
recruited a nationally representative sample in the United States. All items in the key measures used in the two studies can be found in S1 and S2 in the Supplementary Documents.

\section{Study 1}

\subsection{Method}

\section{Participants}

A sample of 199 students from a university in Singapore who had been living locally for at least 7 years participated in the study. The survey included a check regarding climate change belief; a student who reported not believing in the happening of climate change was dropped. Thus, the final sample comprised 198 participants (127 females; age ranged from 18 to 31 years; $M=22.08$ and $S D=1.77$ ). Each participant was compensated with course credits.

We expected a small to medium correlation between perceived cultural impacts of climate change and climate action (based on previous studies regarding the associations between environmental concern and pro-environmental behavior). According to G*Power 3.1.9.2, to detect a correlation at .20 level, with power $=.80$ and alpha $=.05$, a sample of at least 191 was needed. Our sample size was sufficiently large.

\section{Measures}

Participants completed a battery of measures at two time points. At Time 1, participants completed the new Perceived Cultural Impacts of Climate Change Scale, plus measures of the hypothesized psychological correlates. A week later, at Time 2, participants completed three measures regarding a pro-mitigation orientation. This prospective design was less susceptible to the biases introduced by the item context effects, which could artificially inflate observed associations (Podsakoff et al., 2003).

The Perceived Cultural Impacts of Climate Change Scale comprised 12 items with a 7point scale $(1=$ strongly disagree to 7 = strongly agree $)$. These items captured the extent to which participants agreed that climate change is endangering or will threaten different aspects 
of human cultures in the world and whether they agreed that mitigating climate change can help preserve human cultures (see Table 1). Three of the items were reversely worded.

Participants completed the following measures for the four hypothesized psychological correlates. First, they completed the 15-item Cosmopolitan Orientation Scale (Leung et al., 2015), with a 7-point scale $(\alpha=.93)$. Next, they completed the Identification with All Humanity Scale (McFarland et al., 2012). The original scale consists of three groups: community, country, and global. In this study, we focused on the nine-item global level only. Participants responded on a 5-point scale, with higher scores indicating stronger identification ( $\alpha=$.83). Then, participants completed the 18-item Generalized Ethnocentrism Scale (Neuliep et al., 2001) on a 7-point scale ( $\alpha=.88)$. They also completed a values measure (Steg et al., 2014). There were 16 values, falling into four clusters: hedonic $(\alpha=.79)$, egoistic $(\alpha=.79)$, altruistic $(\alpha=.74)$, and biospheric $(\alpha=.87)$. Participants indicated the importance of each value on a 5-point scale.

We included three measures of engagement in climate action. The first two measures were adopted from the 24-country study by Bain et al. (2016) and covered private-sphere and public-sphere mitigation behavior (12 items each). Participants indicated how likely they were to engage in each action on a 5-point scale ( $\alpha \mathrm{s}=.85$ and .91). For actions not possible for them to perform, they could indicate “not applicable.” In the third measure, participants were told that a nation's development was typically evaluated by its economic output, but in recent years alternative indicators had been called for. They were then asked to indicate how much they wanted each of four listed national indicators (economic output, life expectancy, life satisfaction, and environmental impact) to be adopted by their government on a 7-point scale.

To examine the convergent validity of our new scale on perceived cultural impacts, we also measured participants’ perception of the co-benefits of mitigating climate change based on Bain et al. (2016). Participants spent a minute thinking about the Singapore society in 2050 
if people have taken action aimed at preventing significant climate change. They were then asked, "how people in Singapore in 2015 will be like, compared to today." They were shown a list of attributes falling into three dimensions: societal development (five attributes) and dysfunction (six attributes) from Bain et al. (2016), and a new dimension regarding cultural sustainability (six attributes). For each attribute, participants explicitly compared the future Singapore society with the present on a 11 -point scale $(-5=$ much worse to $+5=$ much improved). They also completed this measure once more with reference to the future of the world in general. In a principal factor analysis, a three-factor structure was consistently found. Two of the societal development items (volunteering, extent of community groups) exhibited double loading; they were therefore dropped $(\alpha \mathrm{s}=.78, .75$, and .87 , respectively, for Singapore; $\alpha \mathrm{s}=.72, .75$, and .88, respectively, for the world).

\subsection{Results}

A principal axis factoring analysis of the Perceived Cultural Impacts of Climate Change Scale revealed that the items' communalities ranged from .28 to .69. The scree plot suggested a one-factor structure (Eigenvalue $=5.89$, variance explained $=49.05 \%)$. The factor loadings ranged from .36 to .84 (see Table 1). Scale reliability was high $(\alpha=.90)$. Overall, the scale was satisfactory psychometrically. Thus, for each individual, we computed a composite score based on the average response across the items. We observed that a majority of the participants agreed with the items. Only $10.6 \%$ of the participants had a score of 4 (the scale mid-point) or below, and 50.5\% of participants had a score higher than 5 (one point above the mid-point). This observed strong awareness was corroborated with the sample mean (5.14), which was significantly different from the mid-point, $t(197)=19.32, p<.001$.

We then examined the correlation between perceived cultural impacts and the proposed correlates. As expected, perceived cultural impacts was positively correlated with cosmopolitan orientation $(r=.21, p=.003)$. It was also correlated with Identification with All 
Humanity, but the relationship was marginally significant $(r=.13, p=.066)$. It was negatively correlated with ethnocentrism $(r=-.33, p<.001)$. As for values, perceived cultural impacts was most strongly associated with biospheric values $(r=.38, p<.001)$, followed by altruistic values ( $r=.28, p<.001)$. It was also associated with hedonic values, but of a weaker size ( $r$ $=.18, p=.013)$. It was almost uncorrelated with egoistic values $(r=.04, p=.561)$. Overall, the pattern was consistent with our expectations. Participants who were more cosmopolitan, identified more strongly with all humanity, or were less ethnocentric reported stronger awareness of the cultural impacts of climate change. Also, higher levels of such awareness were found among participants who endorsed universalism (biospheric and altruistic values) more strongly.

We also examined how perception of cultural impacts was associated with perceived cobenefits of climate change mitigation. It was associated with perceived local societal development $(r=.15, p=.041)$ and cultural preservation $(r=22, p=.002)$, as well as global societal development $(r=.22, p=.002)$ and cultural preservation $(r=.18, p=.012)$. It was not significantly associated with perceived local dysfunction $(r=-.12, p=.096)$ or global dysfunction $(r=-.06, p=.407)$. As expected, participants who reported stronger awareness of the cultural impacts of climate change perceived that climate change mitigation would generate a future Singapore and a future world wherein human cultures are better preserved. They also perceived greater co-benefits in terms of societal development.

Finally, we tested our hypotheses regarding the behavioral effect of perceived cultural impacts. Perceived cultural impacts was associated with intentions to perform both privatesphere $(r=.18, p=.010)$ and public-sphere mitigation behavior $(r=.31, p<.001)$. It was also associated with support for using environmental impact as an indicator to inform national development $(r=.33, p<.001)$. It was associated with support for national indicators of life expectancies and life satisfaction to a lesser extent $(r=.19, p=.008$, and $r=.23, p=.001)$, 
but not with support for an economic output indicator ( $r=.06, p=.374)$.

Next, we examined the unique predictive power of perceived cultural impacts beyond age, gender, and the psychological correlates. In Model 1, age, gender, and the psychological correlates were included as predictors. In Model 2, perceived cultural impacts was added. Table 2 shows the outputs. For public-sphere mitigation behavior, in addition to cosmopolitan orientation, identification with all humanity, and biospheric values, perceived cultural impacts was a significant predictor. A similar pattern was found for support for an environmental impact indicator. Unexpectedly, for private-sphere mitigation behavior, only cosmopolitan orientation was a significant predictor. Figure 1 visualizes a comparison of the standardized coefficients of all predictors regarding public-sphere behavior and support for an environmental impact indicator. Perceived cultural impacts was either the strongest or second strongest predictor.

In sum, as hypothesized, perceived cultural impacts predicted intentions to engage in public-sphere mitigation behavior and support for monitoring the country's environmental impact. This effect held despite the control of demographic and psychological correlates, some of which were robustly predictive of PEB (e.g., cosmopolitan orientation, values). Notably, perceived cultural impacts was among the strongest predictors. Unexpectedly, perceived cultural impacts did not predict private-sphere mitigation behavior. A possible reason is that participants did not believe that their personal action can make a difference in preserving cultures from the threat of climate change. We examined whether this null effect was replicable in Study 2.

\section{Study 2}

Findings regarding human responses to environmental problems need to be validated cross-culturally (Tam \& Chan, 2017; Tam \& Milfont, 2020). Study 2 was a pre-registered study (https://osf.io/h3de2/?view_only=7052bb23e0fd48c2818d035df170be36) aiming to 
replicate the previous findings with a sample from the United States.

Study 2 has four strengths, compared to Study 1 . First, the sample was more representative and diverse; it allowed us to examine the association between perceived cultural impacts and a wider range of participants' demographic factors, as well as their political orientation and other climate change opinions. Second, it enabled us to rigorously test the unique effect of perceived cultural impacts on climate action when these other factors were controlled for. Third, we included a wider range of measures for climate action. In addition to behavior in the private and public spheres, we also measured participants' support for climate policy and political engagement in climate change. Fourth, we included an openended question wherein we explicitly asked the participants to describe the examples or cases they had been thinking about when considering the cultural impacts of climate change. Thus, supplementing the quantitative findings, we were able to probe further into participants’ understanding of the cultural impacts from a qualitative angle.

\subsection{Method}

\section{Participants}

Participants were recruited from Prolific Academic, an online panel known to have good data quality (Peer et la., 2017). Interlocked quota sampling was used to obtain a sample that approximated the adult population in the United States with respect to gender, age, and ethnicity. There were 646 participants, but 75 participants were dropped based on three checks. First, participants who reported "No" or "Don’t know" to the question on whether climate change is happening were flagged. Second, as extremely short response times are diagnostic of careless responding (Wood et al., 2017), the eight participants who completed the Perceived Cultural Impacts of Climate Change Scale, the key measure, at response times faster than 1s per item were flagged. Third, we adopted an instructional manipulation check as a check of inattentiveness (Hauser \& Schwarz, 2016). Presented just before the demographics 
questions, this check was a lure question about personality, wherein participants had to ignore the question and type in a given answer; 14 participants failed this check. In total, 68 participants failed one check, seven participants failed two, and nobody failed all three. After dropping them, there were 571 participants (male: 48.51\%, female: 51.49\%; age 18-24: 9.81\%, age 25-34: 22.42\%, age 35-44: $18.39 \%$, age 45-54: 15.94\%, age 55-64: $21.37 \%$, age 65+: 12.08\%; Asian: 8.06\%, Black: 12.26\%, White: 73.91\%, Mixed: 3.33\%, Others: 2.45\%). Each participant was compensated GBP2.

Based on Study 1, we assumed the association between perceived cultural impacts and climate action and policy support to be at least .20 . Testing this correlation with power $=.80$ and alpha $=.05$ required at least 191 participants. We conservatively assumed that the $R^{2}$ increase brought by perceived cultural impacts beyond the covariates to be at least .02 (i.e., a small effect). Testing this effect with power $=.80$ and alpha $=.05$ required a sample of at least 387 participants. Our sample size was sufficient for testing these effects.

\section{Measures}

Participants completed the Perceived Cultural Impacts of Climate Change Scale developed in Study 1. A confirmatory factor analysis revealed that the one-factor model reached acceptable fit (based on CFI, TFI, SRMR, and RMSEA) (MacCallum et al., 1996). The items' factor loadings ranged from .57 to .87. The reliability was high $(\alpha=.95)$. Overall, the scale's structure was confirmed (see Table 1). After completing this measure, participants were asked an open-ended question to explain in detail what kinds of impacts and cultures they had been thinking about when completing the scale.

Participants completed two measures of climate action. The first one was the privatesphere mitigation behavior measure in Study 1. Participants indicated how likely they would engage in each action on a 4-point scale (with an additional option of "not applicable"; $\alpha$ $=.86)$. The second one was a 13-item measure of climate activism adopted from Leiserowitz 
et al. (2019a). Participants indicated their likelihood of engaging in each action on a 4-point scale (with an additional option "prefer not to answer"; $\alpha=.95$ ).

Participants completed a measure regarding their support for 10 domestic climate- and energy-related policies adopted from Leiserowitz et al. (2019b). Seven policies were proclimate and three were supportive of the fossil fuel industry. Participants responded on a fourpoint scale. As an exploratory factor analysis indicated that these policies neatly fell into two factors, we computed for each individual a composite score for support for climate policy ( $\alpha$ $=.84$ ) and another for support for fossil fuel industry $(\alpha=.87)$. Next, participants were asked if they supported the U.S. participation in the Paris Agreement and if they supported President Trump pulling the U.S. out of the Paris Agreement on a 4-point scale. These two items were strongly interrelated $(r=-.90, p<.001)$ and therefore combined as an overall indicator. Finally, participants indicated how important climate change would be to their voting decisions in the 2020 Presidential election on a 4-point scale.

As for the covariates, participants reported their gender, age group $(1=18$ to 24 years to $6=65$ years and above), and their ethnicity (Asian, Black, White, Mixed, and Others). As over $70 \%$ of the participants were White, we dummy coded ethnicity $(0=$ non-White, $1=$ White). Participants also reported their education level $(1=$ less than high school to $5=$ Master's degree or above) and annual household income ( $1=$ less than $\$ 25,000$ to $7=$ $\$ 150,000$ or move). Participants reported their political orientation on a 5-point scale (from very conservative to very liberal) and their partisanship (Republican, Democrat, independent or other, and no party). Partisanship was transformed into three dummy codes, with Democrat as the reference category.

Participants reported their belief in anthropogenic causes of climate change by picking one of four options. We dummy coded this item (1 = picking “caused mostly by human activities”, 0 = picking the others). They also reported their belief in scientific consensus of 
climate change by picking one of four options. We dummy coded this item ( 1 = picking "Most scientists think climate change is happening”, $0=$ picking the others). We also included two items of harm perception. Participants reported how much they thought climate change would harm themselves and people in the U.S. on a 4-point scale.

\subsection{Results}

As in Study 1, we observed that a majority of the participants exhibited awareness of the cultural impacts of climate change. Whereas $63.75 \%$ of the participants had a composite score higher than 5, only $14.36 \%$ of the participants had a score of 4 or below. This observed strong awareness was corroborated with the sample mean (5.25), which was significantly different from the mid-point, $t(571)=5.25, p<.001$.

Next, we examined the correlation between perceived cultural impacts and the proposed correlates. Perceived cultural impacts was weaker among male $(r=-.11, p=.011)$ and stronger among the more educated $(r=.11, p=.010)$. It was not significantly associated with age ( $r=-.06, p=.156)$, being White $(r=-.02, p=.687)$, nor income $(r=.02, p=.706)$. It was strongly associated with being liberal $(r=.47, p<.001)$. A one-way ANOVA showed that there was a significant effect of partisanship, $F(3,567)=32.11, p<.001$. Perceived cultural impacts was lowest among Republican participants $(M=4.30)$ and highest among Democrat participants $(M=5.62)$, with independent or other participants $(M=5.07)$ and no party participants $(M=5.00)$ in between. Bonferroni post-hoc comparisons showed that all pairs were significantly different from each other $(p s \leq .005)$, except for that between independent or other participants and no party ones $(p=1.000)$. Perceived cultural impacts was strongly associated with climate change opinions. It was associated with beliefs in anthropogenic causes $(r=.49, p<.001)$ and scientific consensus $(r=.36, p<.001)$. It was also associated with perceived harms to self $(r=.55, p<.001)$ and Americans $(r=.65, p<.001)$.

Overall, there was not a discernible pattern regarding the relationship between perceived 
cultural impacts and demographic backgrounds (even the significant associations were small). As expected, perceived cultural impacts was weaker among conservatives than liberals, and there was an obvious divide between Republicans and Democrats. In addition, participants who held positive climate opinions and stronger perception of personal and national harms of climate change reported stronger awareness of its cultural impacts.

We then tested whether perceived cultural impacts motivated climate action and climate policy support as hypothesized. Perceived cultural impacts was strongly associated with intentions to engage in both private-sphere mitigation behavior $(r=.43)$ and climate activism $(r=.59)$. It was also strongly associated with support for climate policies $(r=.62)$ and the U.S. participation in the Paris Agreement $(r=.63)$ and importance of climate change in voting decisions $(r=.60)$. Last, it was negatively associated with support for fossil fuel industry $(r=$ $-.47)(p s<.001)$.

Next, we examined the unique predictive power of perceived cultural impacts. In Model 1, demographic variables, political ideology and partisanship, and climate opinions were included as predictors. In Model 2, perceived cultural impacts was added. Across all outcomes, perceived cultural impacts was always a significant predictor (see Table 3). The only other consistent predictor was belief in anthropogenic causes of climate change. Political ideology was significant for five of the outcomes. Figures 2 to 4 visualize comparisons of the standardized coefficients of the predictors. Perceived cultural impacts was always the strongest or second strongest predictor.

In sum, as expected, perceived cultural impacts robustly predicted climate action and climate policy support. This predictive power was not reducible to the effects of demographic backgrounds, political orientation, or general beliefs and harm perceptions regarding climate change. Unlike Study 1, perceived cultural impacts predicted private-sphere climate action as well, possibly because Study 2 was more powered than Study 1, and its sample was more 
diverse and showed more variations in both perceived cultural impacts and private-sphere behavior.

We then explored participants' responses to the open-ended question. We followed the inductive and semantic approach of thematic analysis (Braun \& Clarke, 2006). We report the detail of this exploratory analysis in S3 in the Supplementary Documents. Briefly speaking, four themes were identified: environmental changes responsible for the cultural impacts, types of people affected by the impacts, regions suffering from the impacts, and aspects of culture impacted. Our participants named a wide range of environmental changes, various communities or populations in different parts of the world, and a multitude of cultural aspects affected. Collectively, the participants appeared to have some concrete understanding of the cultural impacts of climate change. This observation corroborates the high average level of awareness as reflected by their scores on the Perceived Cultural Impacts of Climate Change Scale. These qualitative responses serve as valuable sources of information for future research to probe into people's lay understanding of the cultural impacts of climate change.

Last, as an exploratory analysis, we conducted a regression analysis to explore the interaction between perceived cultural impacts of climate change and political orientation on climate change engagement and found an interesting pattern. Specifically, the analysis revealed that the association between political orientation and climate policy support was weaker among participants whose awareness of the cultural impacts of climate change was high (see S4 in the Supplementary Documents for more details). We discuss this result in the general discussion.

\section{General Discussion}

The impacts of climate change on human cultures receive increasing attention in recent years (Fatorić \& Seekamp, 2017). To what extent are people aware of these impacts? Does such awareness motivate engagement in climate change? Who shows more of such 
awareness? The present investigation provides the very first set of answers to these questions. In the following, we discuss the theoretical and practical significance of what we observed with respect to these three questions.

\subsection{Public Understanding of Climate Change Impacts}

In previous research surveying people’s understanding of climate change impacts (e.g., Maibach et al., 2011), the cultural domain was not considered. The present findings fill this void. We measured people's perceptions of the cultural impacts of climate change and observed individual differences in such perceptions; yet, on aggregate, in the two samples across different demographics (an Asian sample of Singaporean college students and a Western sample of American adults), there was a high level of awareness of the issue. The current research presents the first attempt to capture and document the public awareness of the cultural impacts brought about by climate change systematically. Moreover, at least among our American sample, participants were able to name a wide variety of cases or examples of these impacts. Extrapolating from these findings, and in line with previous research (e.g., Hathaway \& Maibach, 2018), it seems that a majority of people do recognize the impacts of climate change on human systems, either in general or in specific domains. Importantly, our findings add the cultural dimension in the study of such global awareness of climate change impacts.

In Study 1, participants who perceived more cultural impacts of climate change were more likely to also perceive cultural co-benefits of climate change mitigation. They projected a better future for human cultures locally and globally if climate change is mitigated. These findings suggest that when it comes to people's perception of the co-benefits of climate change mitigation, cultural sustainability is a distinct category, in addition to societal development and dysfunction identified by Bain et al. (2016).

Our findings also identify what kinds of individuals are more aware of the cultural 
impacts of climate change. It appears that individuals with a more global perspective and a more expansive sense of morality are more ready to perceive such impacts. Notably, there is also a political divide: Conservatives are less likely to recognize the threat of climate change to cultures. This observation is in agreement with what has been generally observed in research on climate change beliefs (Hornsey et al., 2016) and concern for environmental issues (Cruz, 2017).

We argue that an important direction for future studies is to measure perceived cultural impacts of climate change in a larger number of countries. The two samples in the present research represented an Asian society and a Western society and involved both students and the general public. However, with these samples only, we cannot tell whether awareness of the cultural impacts is prevalent globally and whether it is more prevalent in some countries than others. Cross-national variations of environmental or climate change beliefs are widely documented (e.g., Franzen \& Vogl, 2013), and research has suggested the imperative to consider societal or cultural contexts when examining environmental attitude and behavior (Tam \& Milfont, 2020). We recommend adding culture-related questions to existing climate opinion polls to promote understanding in this regard. It is also worth exploring in a crossnational study whether the individual difference factors identified here (e.g., political orientation, cosmopolitan orientation) predict perceived cultural impacts to similar or different extents in different societies, as pathways to environmental beliefs could vary across contexts (Tam \& Chan, 2017).

\subsection{Public Engagement in Climate Change Mitigation}

The association between perceived cultural impacts and engagement in climate change mitigation was very robust across the two studies. Participants who perceived the cultural impacts reported stronger intentions to engage in mitigation action, support for climate policy, rejection of fossil fuel industry, and political engagement in climate change. This association 
held when an array of psychological, demographic, and political factors, as well as general climate change opinions, were controlled for. Importantly, perception of cultural impacts was always the strongest or second strongest predictor, suggesting its robust predictive power.

Given its correlational nature, we cannot draw any causal inference from this research. Nevertheless, our findings hint at the motivating effect of perceived cultural impacts on climate action. It is conceivable that drawing people's attention to the threat of climate change on human cultures could be a potent way to mobilize the public. This speculation has the potential to contribute to the study of climate change communication (Moser, 2010). It has been shown that issue framing, wherein the audience is exposed to a message that frames climate change in societal or human as opposed to environmental terms, can increase public engagement in climate action (Wibeck, 2014). The present findings add to this area of study by highlighting the potential of a cultural sustainability frame. It is worth testing whether framing climate change as pertaining to cultural issues carries similar effects as the other well-tested frames (e.g., health, economy). If findings are positive, climate change communicators will have another powerful tool at their disposal.

It is also important to note that there is no one-size-fits-all approach in communication (Moser, 2010). Given the audience’s characteristics, some frames are more effective than others. This view has been corroborated in the psychological research of persuasion supporting the message tailoring effect—a message is more persuasive when its contents are congruent with the recipients’ motivations (Dijkstra, 2008; Tam, 2015). Future research should also consider for what kinds of individuals the proposed cultural sustainability frame is more persuasive.

There is a well-documented political divide in environmentalism (Cruz, 2017). In the present study, we also observed a political divide in perceived cultural impacts. Notably, recent studies have suggested that messages that appeal to values shared by people across the 
political spectrum (e.g., health, liberty) can narrow the divide (e.g., Petrovic et al., 2014; Wolsko, 2017). Accordingly, another direction worth pursuing is whether the proposed cultural sustainability frame can moderate the political divide in perceived cultural impacts and hence climate change action. Though correlational, our exploratory analysis in Study 2 did reveal such a moderating effect. That is, the political divide on some of the outcome variables was weaker among participants whose awareness of the cultural impacts of climate change was high. A future experiment can aim at testing this interaction more rigorously.

\section{Conclusion}

Was David Katoatau's effort successful in raising the global public's awareness of the impacts of climate change on his country and culture? It is difficult to tell. Nevertheless, our findings suggest that, at least among the participants we examined, awareness of the cultural impacts was generally high. Most important, such awareness seems capable of mobilizing people to engage in climate change mitigation. These findings not only add a cultural dimension to our understanding of how the public understand and respond to climate change but also reveal a viable utilization of cultural frames or appeals as an effective public communication strategy. 


\section{References}

Adger, W. N., Barnett, J., Brown, K., Marshall, N., \& O'brien, K. (2013). Cultural dimensions of climate change impacts and adaptation. Nature Climate Change, 3(2), 112-117. https://doi.org/10.1038/nclimate1666

Anderson, D. G., Bissett, T. G., Yerka, S. J., Wells, J. J., Kansa, E. C., Kansa, S. W., ... \& White, D. A. (2017). Sea-level rise and archaeological site destruction: An example from the southeastern United States using DINAA (Digital Index of North American Archaeology). PloS ONE, 12(11), e0188142. https://doi.org/10.1371/journal.pone.0188142

Bain, P. G., Milfont, T. L., Kashima, Y., Bilewicz, M., Doron, G., Garðarsdóttir, R. B., ... \& Corral-Verdugo, V. (2016). Co-benefits of addressing climate change can motivate action around the world. Nature Climate Change, 6(2), 154-157. https://doi.org/10.1038/nclimate2814

Bizumic, B., \& Duckitt, J. (2012). What is and is not ethnocentrism? A conceptual analysis and political implications. Political Psychology, 33(6), 887-909. https://doi.org/10.1111/j.1467-9221.2012.00907.x

Braun, V., \& Clarke, V. (2006). Using thematic analysis in psychology. Qualitative Research in Psychology, 3(2), 77-101. https://doi.org/10.1191/1478088706qp063oa

Cruz, S. M. (2017). The relationships of political ideology and party affiliation with environmental concern: A meta-analysis. Journal of Environmental Psychology, 53, 8191. https://doi.org/10.1016/j.jenvp.2017.06.010

DeBono, R., Vincenti, K., \& Calleja, N. (2012). Risk communication: Climate change as a human-health threat, a survey of public perceptions in Malta. The European Journal of Public Health, 22(1), 144-149. https://doi.org/10.1093/eurpub/ckq181

DeVellis, R. (2003). Scale development: Theory and applications. Thousand Oaks: Sage.

Dijkstra, A. (2008). The psychology of tailoring-ingredients in computer-tailored persuasion. Social and Personality Psychology Compass, 2(2), 765-784. https://doi.org/10.1111/j.1751-9004.2008.00081.x

Doyle, J. (2007). Picturing the clima(c)tic: Greenpeace and the representational politics of climate change communication. Science as Culture, 16, 129-150. https://doi.org/10.1080/09505430701368938

Fatorić, S., \& Seekamp, E. (2017). Are cultural heritage and resources threatened by climate change? A systematic literature review. Climatic Change, 142(1-2), 227-254. https://doi.org/10.1007/s10584-017-1929-9

Franzen, A., \& Vogl, D. (2013). Two decades of measuring environmental attitudes: A comparative analysis of 33 countries. Global Environmental Change, 23(5), 1001-1008. https://doi.org/10.1016/j.gloenvcha.2013.03.009 
Haque, M. A., Yamamoto, S. S., Malik, A. A., \& Sauerborn, R. (2012). Households' perception of climate change and human health risks: A community perspective. Environmental Health, 11(1), 1-12. https://doi.org/10.1186/1476-069X-11$\underline{1}$

Hathaway, J., \& Maibach, E. W. (2018). Health implications of climate change: a review of the literature about the perception of the public and health professionals. Current Environmental Health Reports, 5(1), 197-204. https://doi.org/10.1007/s40572-018$\underline{0190-3}$

Hauser, D. J., \& Schwarz, N. (2016). Attentive Turkers: MTurk participants perform better on online attention checks than do subject pool participants. Behavior Research Methods, 48(1), 400-407. https://doi.org/10.3758/s13428-015-0578-z

Holtz, D., Markham, A., Cell, K., \& Ekwurzel, B. (2014). National landmarks at risk. Union of Concerned Scientists.

Hornsey, M. J., Harris, E. A., Bain, P. G., \& Fielding, K. S. (2016). Meta-analyses of the determinants and outcomes of belief in climate change. Nature Climate Change, 6(6), 622-626. https://doi.org/10.1038/nclimate2943

Hornsey, M. J., Harris, E. A., \& Fielding, K. S. (2018). Relationships among conspiratorial beliefs, conservatism and climate scepticism across nations. Nature Climate Change, 8(7), 614-620. https://doi.org/10.1038/s41558-018-0157-2

Intergovernmental Panel on Climate Change. (2014). Fifth assessment report. Retrieved from http://www.ipcc.ch/report/ar5/

Jann, B. (2014). Plotting regression coefficients and other estimates. The Stata Journal, 14(4), 708-737.

Katoatau, D. (n.d.). Save our country. Retrieved from http://www.climate.gov.ki/wpcontent/uploads/2015/09/ANNEX-2-David-Katoatau.pdf

Leiserowitz, A., Maibach, E., Rosenthal, S., Kotcher, J., Bergquist, P., Gustafson, A., Ballew, M., \& Goldberg, M. (2019a). Climate Activism: Beliefs, Attitudes, and Behaviors, November 2019. Yale University and George Mason University. New Haven, CT: Yale Program on Climate Change Communication.

Leiserowitz, A., Maibach, E., Rosenthal, S., Kotcher, J., Bergquist, P., Gustafson, A., Ballew, M., \& Goldberg, M. (2019b). Politics \& Global Warming, November 2019. Yale University and George Mason University. New Haven, CT: Yale Program on Climate Change Communication. https://doi.org/10.31234/osf.io/k63gs

Leung, A. K-Y., Koh, K., \& Tam, K-P. (2015). Being environmentally responsible: Cosmopolitan orientation predicts pro-environmental behaviors. Journal of Environmental Psychology, 43, 79-94. https://doi.org/10.1016/j.jenvp.2015.05.011

MacCallum, R. C., Browne, M. W., \& Sugawara, H. M. (1996). Power analysis and determination of sample size for covariance structure modeling. Psychological 
Methods, 1(2), 130-149. https://doi.org/10.1037/1082-989X.1.2.130

Maibach, E. W., Leiserowitz, A., Roser-Renouf, C., \& Mertz, C. K. (2011). Identifying likeminded audiences for global warming public engagement campaigns: An audience segmentation analysis and tool development. PloS one, 6(3), e17571. https://doi.org/10.1371/journal.pone.0017571

Maibach, E. W., Nisbet, M., Baldwin, P., Akerlof, K., \& Diao, G. (2010). Reframing climate change as a public health issue: An exploratory study of public reactions. BMC Public Health, 10(1), 299. https://doi.org/10.1186/1471-2458-10-299

Marzeion, B., \& Levermann, A. (2014). Loss of cultural world heritage and currently inhabited places to sea-level rise. Environmental Research Letters, 9(3), 034001. https://doi.org/10.1088/1748-9326/9/3/034001

McDonald, R. I., Chai, H. Y., \& Newell, B. R. (2015). Personal experience and the 'psychological distance'of climate change: An integrative review. Journal of Environmental Psychology, 44, 109-118. https://doi.org/10.1016/j.jenvp.2015.10.003

McFarland, S., Webb, M., \& Brown, D. (2012). All humanity is my ingroup: A measure and studies of identification with all humanity. Journal of Personality and Social Psychology, 103(5), 830-853. https://doi.org/10.1037/a0028724

Mildenberger, M., Marlon, J. R., Howe, P. D., \& Leiserowitz, A. (2017). The spatial distribution of Republican and Democratic climate opinions at state and local scales. Climatic Change, 145(3), 539-548. https://doi.org/10.1007/s10584-017-2103-0

Moser, S. C. (2010). Communicating climate change: History, challenges, process and future directions. Wiley Interdisciplinary Reviews: Climate Change, 1(1), 31-53. https://doi.org/10.1002/wcc.11

Neuliep, J. W., Chaudoir, M., \& McCroskey, J. C. (2001). A cross-cultural comparison of ethnocentrism among Japanese and United States college students. Communication Research Reports, 18(2), 137-146. https://doi.org/10.1080/08824090109384791

Opotow, S., \& Weiss, L. (2000). New ways of thinking about environmentalism: Denial and the process of moral exclusion in environmental conflict. Journal of Social Issues, 56(3), 475-490. https://doi.org/10.1111/0022-4537.00179

Peer, E., Brandimarte, L., Samat, S., \& Acquisti, A. (2017). Beyond the Turk: Alternative platforms for crowdsourcing behavioral research. Journal of Experimental Social Psychology, 70, 153-163. https://doi.org/10.1016/j.jesp.2017.01.006

Petrovic, N., Madrigano, J., \& Zaval, L. (2014). Motivating mitigation: when health matters more than climate change. Climatic Change, 126(1), 245-254. https://doi.org/10.1007/s10584-014-1192-2

Podsakoff, P. M., MacKenzie, S. B., Lee, J. Y., \& Podsakoff, N. P. (2003). Common method biases in behavioral research: A critical review of the literature and recommended remedies. Journal of Applied Psychology, 88(5), 879-903. https://doi.org/10.1037/0021- 
Poushter, J., \& Huang, C. (February 10, 2019). Climate change still seen as the top global threat, but cyberattacks a rising concern. Retrieved from https://www.pewresearch.org/global/2019/02/10/climate-change-still-seen-as-the-topglobal-threat-but-cyberattacks-a-rising-concern/

Rigby, C. W., Rosen, A., Berry, H. L., \& Hart, C. R. (2011). If the land's sick, we're sick: The impact of prolonged drought on the social and emotional well-being of Aboriginal communities in rural New South Wales. Australian Journal of Rural Health, 19(5), 249254. https://doi.org/10.1111/j.1440-1584.2011.01223.x

Schwartz, S. H. (1992). Universals in the content and structure of values: Theoretical advances and empirical tests in 20 countries. Advances in experimental social psychology, 25, 1-65. https://doi.org/10.1016/S0065-2601(08)60281-6

Skrbis, Z., Kendall, G., \& Woodward, I. (2004). Locating cosmopolitanism: Between humanist ideal and grounded social category. Theory, Culture \& Society, 21(6), 115-136. https://doi.org/10.1177/0263276404047418

Smith, M. (September 15, 2019). International poll: Most expect to feel impact of climate change, many think it will make us extinct. Retrieved from https://yougov.co.uk/topics/science/articles-reports/2019/09/15/international-poll-mostexpect-feel-impact-climate

Spence, A., Poortinga, W., \& Pidgeon, N. (2012). The psychological distance of climate change. Risk Analysis: An International Journal, 32(6), 957-972.

https://doi.org/10.1111/j.1539-6924.2011.01695.x

Steg, L., Perlaviciute, G., Van der Werff, E., \& Lurvink, J. (2014). The significance of hedonic values for environmentally relevant attitudes, preferences, and actions. Environment and Behavior, 46(2), 163-192. https://doi.org/10.1177/0013916512454730

Tam, K-P. (2015). Are anthropomorphic persuasive appeals effective? The role of the recipient's motivations. British Journal of Social Psychology, 54, 187-200. https://doi.org/10.1111/bjso.12076

Tam, K-P., \& Chan, H-W. (2017). Environmental concern has a weaker association with proenvironmental behavior in some societies than others: A cross-cultural psychology perspective. Journal of Environmental Psychology, 53, 213-223. https://doi.org/10.1016/j.jenvp.2017.09.001

Tam, K-P., \& Milfont, T. L. (2020). Towards cross-cultural environmental psychology: A state-of-the-art review and recommendations. Journal of Environmental Psychology, 71, 101474. https://doi.org/10.1016/j.jenvp.2020.101474

UNESCO (2001). UNESCO Universal Declaration on Cultural Diversity. UNESCO.

UNESCO (2007). Case studies on climate change and world heritage. UNESCO. 
United Nations. (2009). State of the world's indigenous peoples. United Nations.

Weiss, K. R. (2015). Before we drown we may die of thirst. Nature, 526(7575), 624-627. https://doi.org/10.1038/526624a

Wibeck, V. (2014). Enhancing learning, communication and public engagement about climate change-some lessons from recent literature. Environmental Education Research, 20(3), 387-411. https://doi.org/10.1080/13504622.2013.812720

Wolsko, C. (2017). Expanding the range of environmental values: Political orientation, moral foundations, and the common ingroup. Journal of Environmental Psychology, 51, 284294. https://doi.org/10.1016/j.jenvp.2017.04.005

Wood, D., Harms, P. D., Lowman, G. H., \& DeSimone, J. A. (2017). Response speed and response consistency as mutually validating indicators of data quality in online samples. Social Psychological and Personality Science, 8(4), 454-464.

https://doi.org/10.1177/1948550617703168 
Table 1. Psychometric properties of The Perceived Cultural Impacts of Climate Change

Scale.

\begin{tabular}{|c|c|c|}
\hline Item & $\begin{array}{c}\text { Study } 1 \\
\text { Factor } \\
\text { loading } \\
\text { (exploratory) } \\
\end{array}$ & $\begin{array}{c}\text { Study } 2 \\
\text { Factor } \\
\text { loading } \\
\text { (confirmatory) }\end{array}$ \\
\hline A lot of cultural heritage will be threatened or endangered by climate change. & .84 & .86 \\
\hline Climate change threatens the survival of some indigenous cultures. & .82 & .87 \\
\hline Climate change threatens cultural diversity in the world. & .82 & .84 \\
\hline $\begin{array}{l}\text { Climate change will drive some cultures, such as island communities, to } \\
\text { disappear entirely. }\end{array}$ & .81 & .80 \\
\hline $\begin{array}{l}\text { Because of climate change, some traditional cultural values and practices will } \\
\text { be lost. }\end{array}$ & .76 & .81 \\
\hline Climate change will not threaten or endanger any culture in the world. (r) & .36 & .69 \\
\hline $\begin{array}{l}\text { Many cultures worldwide are fragile and unable to adapt to the impacts } \\
\text { brought about by climate change. }\end{array}$ & .76 & .73 \\
\hline Climate change will not reduce cultural diversity in the world. (r) & .42 & .85 \\
\hline $\begin{array}{l}\text { To protect traditional cultures, we need to do more to reduce the impacts of } \\
\text { climate change. }\end{array}$ & .75 & .85 \\
\hline By fighting climate change, we can preserve some important cultural heritage. & .73 & .85 \\
\hline $\begin{array}{l}\text { One way to save indigenous communities worldwide is to mitigate climate } \\
\text { change. }\end{array}$ & .66 & .82 \\
\hline $\begin{array}{l}\text { Mitigating climate change cannot help us preserve cultural diversity in the } \\
\text { world. (r) }\end{array}$ & .41 & .57 \\
\hline Reliability & .90 & .95 \\
\hline Sample mean & 5.14 & 5.25 \\
\hline Sample SD & .83 & 1.20 \\
\hline Chi-square & & 380.07 \\
\hline df & & 54 \\
\hline$p$ & & $<.001$ \\
\hline CFI & & .94 \\
\hline TLI & & .93 \\
\hline SRMR & & .04 \\
\hline RMSEA & & .10 \\
\hline
\end{tabular}

Notes. The instruction of the scale read: "Below are some statements about how climate change might affect cultures around the world. Please indicate the extent that you agree or disagree with these statements.” $\mathrm{r}=$ reversely worded items. 
Table 2. Results of regression models predicting climate action in Study 1.

\begin{tabular}{lccc}
\hline Predictor & $\begin{array}{c}\text { Outcomes } \\
\text { Private-sphere } \\
\text { mitigation behavior }\end{array}$ & $\begin{array}{c}\text { Public-sphere } \\
\text { mitigation behavior }\end{array}$ & $\begin{array}{c}\text { Support for an } \\
\text { environmental } \\
\text { impact indicator }\end{array}$ \\
\hline Age & $.01(.03)$ & $.01(.03)$ & $.04(.05)$ \\
Gender $(0=$ female, $1=$ male $)$ & $-.15(.11)$ & $-.26 *(.11)$ & $-.11(.20)$ \\
Cosmopolitan orientation & $.37 * *(.09)$ & $.33^{* * *}(.09)$ & $.20(.16)$ \\
Identification with all humanity & $.13(.10)$ & $.21^{*}(.10)$ & $-.12(.17)$ \\
Ethnocentrism & $-.06(.09)$ & $.14(.09)$ & $-.22(.15)$ \\
Hedonic values & $-.07(.07)$ & $.02(.07)$ & $-.15(.13)$ \\
Egoistic values & $.02(.08)$ & $-.03(.08)$ & $.10(.14)$ \\
Altruistic values & $.11(.10)$ & $.01(.10)$ & $.12(.17)$ \\
Biospheric values & $.04(.07)$ & $.15 *(.13)$ & $.15)$ \\
Perceived cultural impacts & $.03(.06)$ & $31.7 \%$ & $.34 * *(.11)$ \\
$R^{2}$ of model & $29.4 \%$ & $2.5 \%$ & $18.1 \%$ \\
$R^{2}$ change from Model 1 & $0.1 \%$ & .009 & $4.3 \%$ \\
$p$ & .628 & & .002 \\
\hline
\end{tabular}

Notes. ${ }^{* * *} p<.001 ; * * p<.01 ; * p<.05 ;{ }^{+} p<.10$. Shown are unstandardized coefficients, with standard errors in brackets. In Model 1 , perceived cultural impacts was not included. 
Table 3. Results of regression models predicting climate action and climate policy support in Study 2.

\begin{tabular}{|c|c|c|c|c|c|c|}
\hline \multirow[b]{2}{*}{ Predictor } & \multicolumn{6}{|c|}{ Outcomes } \\
\hline & $\begin{array}{l}\text { Private-sphere } \\
\text { mitigation behavior }\end{array}$ & Climate activism & $\begin{array}{l}\text { Support for climate } \\
\text { policy }\end{array}$ & $\begin{array}{l}\text { Support for fossil } \\
\text { fuel industry }\end{array}$ & $\begin{array}{l}\text { Support for the } \\
\text { U.S. participation } \\
\text { in the Paris } \\
\text { Agreement }\end{array}$ & $\begin{array}{c}\text { Importance of } \\
\text { climate change in } \\
\text { voting decisions }\end{array}$ \\
\hline Age & $.04^{* *}(.01)$ & $.01(.02)$ & $.01(.01)$ & $-.06^{* *}(.02)$ & $.01(.01)$ & $.05^{* *}(.02)$ \\
\hline Gender ( 0 = female, $1=$ male $)$ & $-.12 * *(.04)$ & $-.06(.05)$ & $-.03(.04)$ & $-.04(.06)$ & $-.10 *(.04)$ & $-.09(.06)$ \\
\hline Ethnicity ( $0=$ non-White, $1=$ White) & $-.02(.04)$ & $.05(.06)$ & $.01(.04)$ & $-.04(.07)$ & $-.08^{+}(.05)$ & $.08(.06)$ \\
\hline Education level & $.03(.02)$ & $.03(.03)$ & $-.03(.02)$ & $.04(.04)$ & $-.03(.03)$ & $-.01(.03)$ \\
\hline Income & $.02 *(.01)$ & $.01(.01)$ & $.02(.01)$ & $-.02(.02)$ & $.02(.01)$ & $.004(.02)$ \\
\hline Political ideology & $-.02(.03)$ & $.09 * *(.03)$ & $.07 * *(.02)$ & $-.17 * * *(.04)$ & $.11^{* * *}(.03)$ & $.12 * *(.04)$ \\
\hline Republican & $.06(.08)$ & $-.14(.10)$ & $.08(.08)$ & $.04(.12)$ & $-.28 * *(.09)$ & $-.47 * * *(.12)$ \\
\hline Independent or other & $.07(.05)$ & $-.03(.06)$ & $-.02(.05)$ & $-.06(.08)$ & $-.03(.06)$ & $-.17 *(.07)$ \\
\hline No party & $-.004(.08)$ & $-.19 *(.10)$ & $-.01(.07)$ & $-.20^{+}(.12)$ & $.12(.08)$ & $-.14(.11)$ \\
\hline Belief in anthropogenic causes & $.19 * *(.06)$ & $.31^{* * *}(.08)$ & $.26^{* * *}(.06)$ & $-.19 *(.09)$ & $.57 * * *(.07)$ & $.51 * * *(.09)$ \\
\hline Belief in scientific consensus & $-.001(.06)$ & $-.13^{+}(.07)$ & $.14 *(.06)$ & $-.30 * *(.09)$ & $.20 * *(.07)$ & $-.11(.09)$ \\
\hline Perceived harm to self & $.11^{* *}(.03)$ & $.25^{* * *}(.04)$ & $.08 * *(.03)$ & $-.04(.05)$ & $.04(.04)$ & $.18 * * *(.05)$ \\
\hline Perceived harm to Americans & $.06(.04)$ & $.03(.05)$ & $.04(.04)$ & $-.07(.06)$ & $.09 *(.04)$ & $.15^{* *}(.06)$ \\
\hline Perceived cultural impacts & $.10^{* * *}(.02)$ & $.17^{* * *}(.03)$ & $.17^{* * *}(.02)$ & $-.15^{* * *}(.04)$ & $.16^{* * *}(.03)$ & $.17^{* * *}(.03)$ \\
\hline$R^{2}$ of model & $28.94 \%$ & $49.58 \%$ & $46.81 \%$ & $32.26 \%$ & $59.83 \%$ & $55.28 \%$ \\
\hline$R^{2}$ change from Model 1 & $2.55 \%$ & $3.31 \%$ & $5.70 \%$ & $2.29 \%$ & $2.88 \%$ & $2.02 \%$ \\
\hline$p$ & $<.001$ & $<.001$ & $<.001$ & $<.001$ & $<.001$ & $<.001$ \\
\hline
\end{tabular}

Notes. ${ }^{* * *} p<.001 ; * * p<.01 ; * p<.05 ;^{+} p<.10$. Shown are unstandardized coefficients, with standard errors in brackets. In Model 1 , perceived cultural impacts was not included. For the partisanship variables, the reference category was "Democrat." 
Figure 1. Comparing standardized regression coefficients in Study 1.

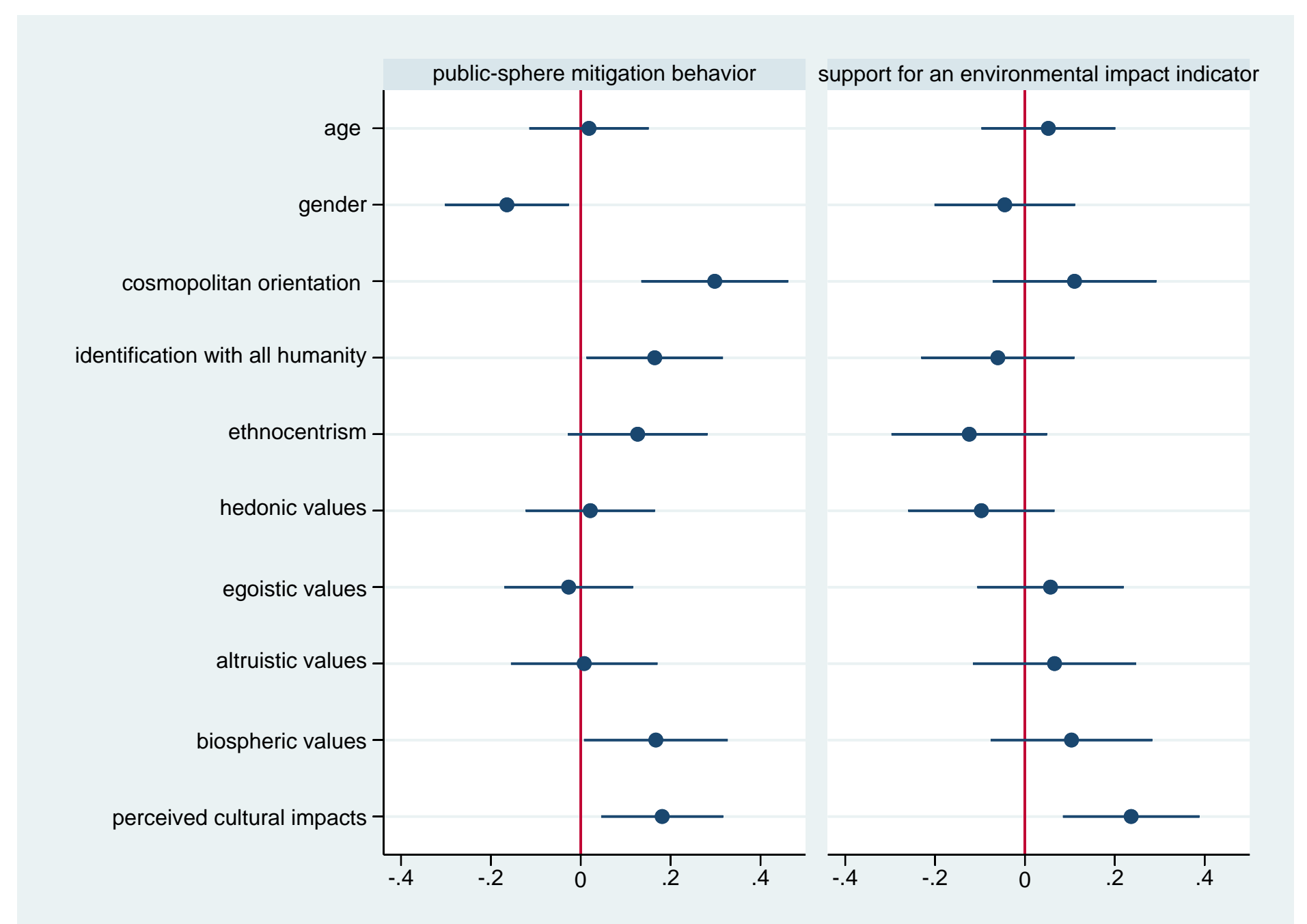

Note. The plot was generated with the coefplot command in Stata developed by Jann (2014). The whiskers stand for 95\% confidence intervals. 
Figure 2. Comparing standardized regression coefficients in Study 2 (private-sphere mitigation behavior and climate activism).

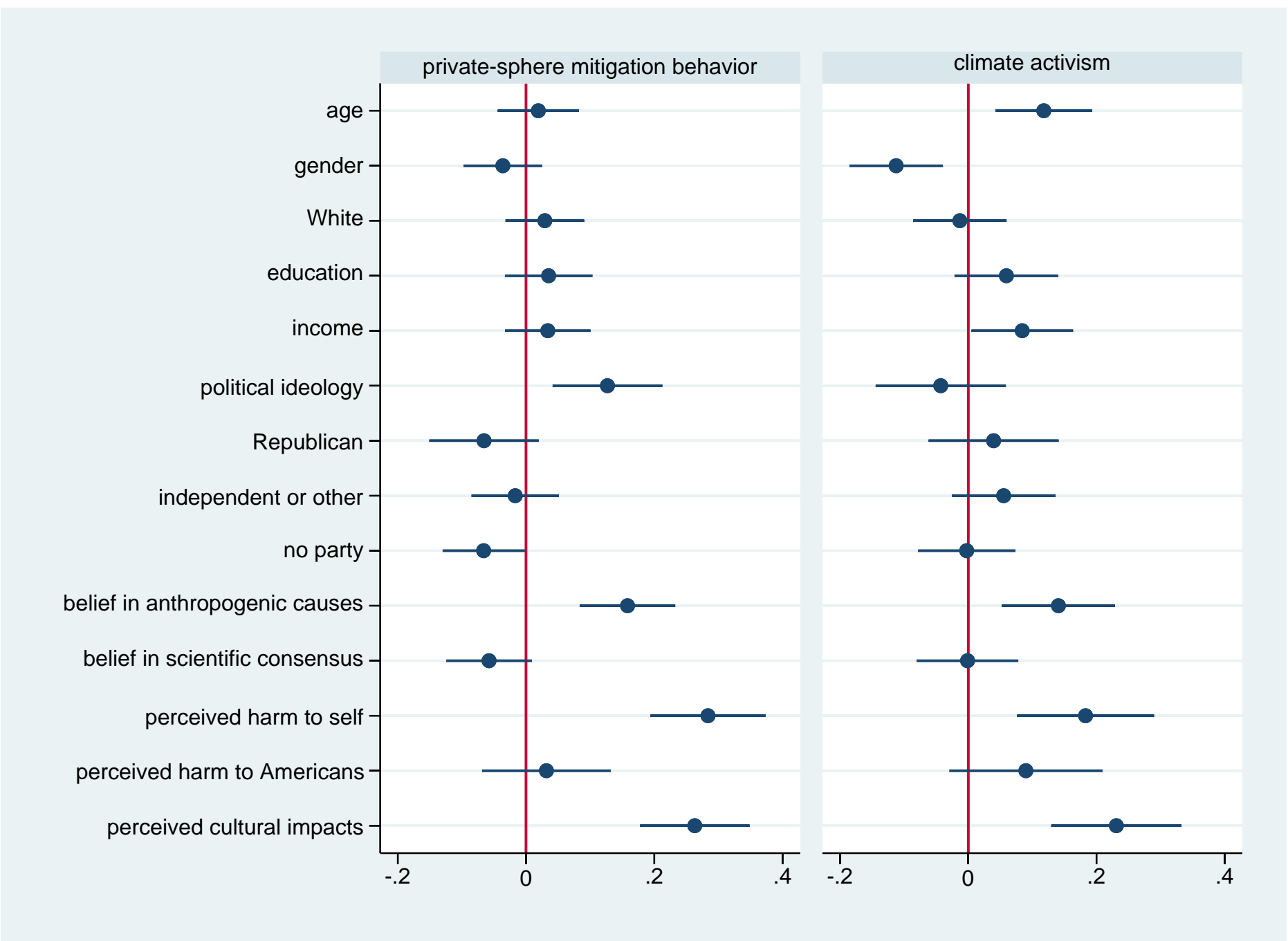


Figure 3. Comparing standardized regression coefficients in Study 2 (support for climate policy and support for fossil fuel industry).

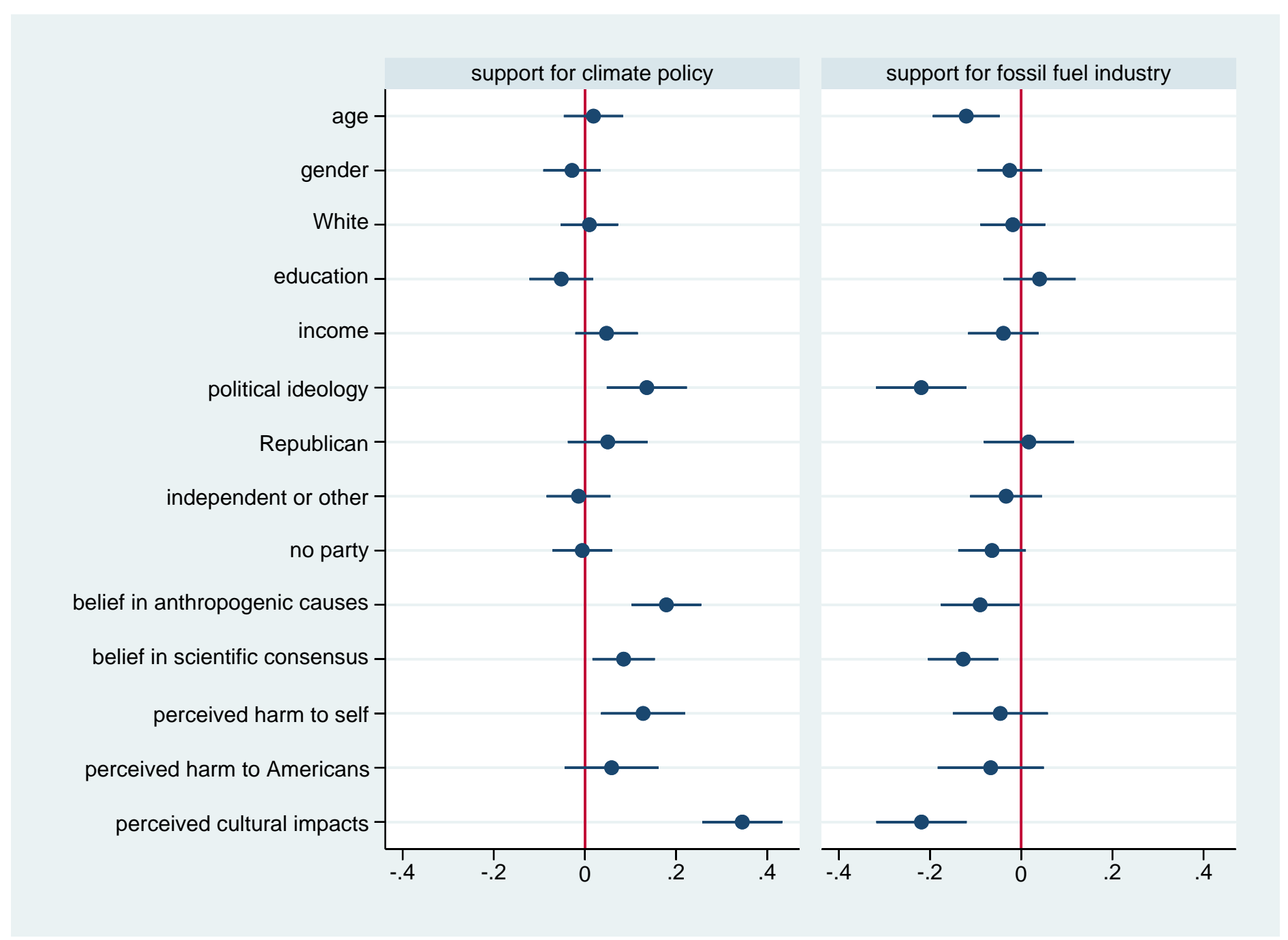


Figure 4. Comparing standardized regression coefficients in Study 2 (support for the U.S. participation in the Paris Agreement and importance of climate change in voting decisions).

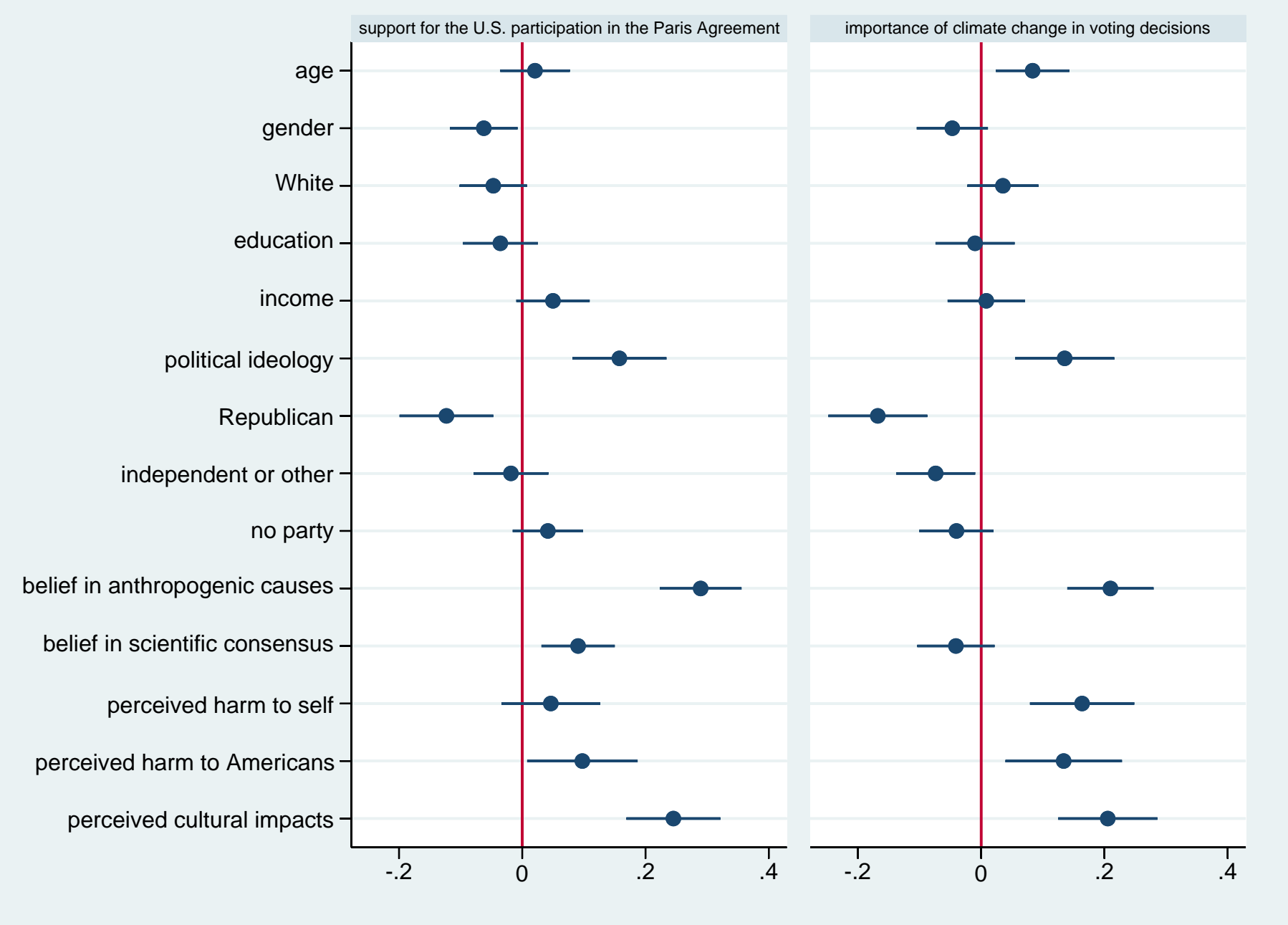




\section{Supplementary Documents}

S1. Measures in Study 1

S2. Measures in Study 2

S3. Analysis of the Open-Ended Responses in Study 2

S4. Exploratory Analysis in Study 2 


\section{S1. Measures in Study 1}

\section{Perceived Cultural Impacts of Climate Change Scale}

Please refer to Table 1 in the main text.

\section{Cosmopolitan Orientation Scale}

1. I would serve the world community by helping human beings.

2. I want to help the unfortunate ones even if they are from other countries.

3. I want to play my part to help make the world a better place for all.

4. I get upset when people do not want to offer help when those in need are foreigners.

5. When people from other countries are in need, I will help them to the best of my abilities.

6. I am open to living in a different culture.

7. I want to travel to experience many different cultures.

8. I am willing to study or work abroad in another culture.

9. It is exciting to immerse in a foreign culture.

10. I enjoy learning more about different cultures in the world.

11. It is important to preserve the authenticity of native cultures.

12. I respect cultural differences.

13. I embrace cultural diversity.

14. We should celebrate cultural differences.

15. I am against having one dominating culture.

\section{Identification with All Humanity Scale}

1. How close do you feel to people all over the world?

2. How often do you use the word "we" to refer to people all over the world?

3. How much would you say you have in common with people all over the world?

4. Sometimes people think of those who are not a part of their immediate family as "family." To what degree do you think of people all over the world as "family"?

5. How much do you identify with (that is, feel a part of, feel love toward, have concern for) people all over the world?

6. How much would you say you care (feel upset, want to help) when bad things happen to people all over the world?

7. How much do you want to be a responsible citizen of the world?

8. How much do you believe in being loyal to all mankind?

9. When they are in need, how much do you want to help people all over the world?

\section{Generalized Ethnocentrism Scale}

1. Most cultures are backward compared to my culture.

2. My culture should be the role model for other cultures.

3. Lifestyles in other cultures are just as valid as those in my culture.

4. Other cultures should try to be like my culture.

5. I'm not interested in the values and customs of other cultures.

6. People in my culture could learn a lot from people in other cultures.

7. Most people from other cultures just don't know what's good for them.

8. I have little respect for the values and customs of other cultures.

9. Most people would be happier if they lived like people in my culture. 
10. People in my culture have just about the best lifestyles of anywhere.

11. Lifestyles in other cultures are not as valid as those in my culture.

12. I'm very interested in the values and customs of other cultures.

13. I respect the values and customs of other cultures.

14. I do not cooperate with people who are different.

15. I do not trust people who are different.

16. I dislike interacting with people from different cultures.

17. Other cultures are smart to look up to my culture.

18. People from other cultures act strange and unusual when they come into my culture.

\section{Values}

Hedonic values:

1. Pleasure (gratification of desire)

2. Enjoying life (enjoying food, sex, leisure, etc.)

3. Gratification for oneself (satisfaction of self-interest)

Egoistic values

1. Social power (control over others, dominance)

2. Wealth (material possessions, money)

3. Authority (the right to lead or command)

4. Influential (having an impact on people and events)

5. Ambitious (hard-working, aspiring)

Altruistic values:

1. Equality (equal opportunity for all)

2. A world at peace (free of war and conflict)

3. Social Justice (correcting injustice, care for the weak)

4. Helpful (working for the welfare of others)

Biospheric values:

1. Preventing pollution (protecting natural resources)

2. Respecting the earth (harmony with other species)

3. Unity with nature (fitting into nature)

4. Protecting the environment (preserving nature)

Private-sphere mitigation behavior

1. Install products to save energy (e.g., low-energy light bulbs)

2. Buy environmentally-friendly products

3. Conserve water at home (e.g., when cooking or showering)

4. Minimize use of air-conditioning or heating

5. Reduce car travel (e.g., walk, cycle, or use public transportation)

6. Turn off lights and appliances when not in use

7. Avoid or reduce eating meat

8. Recycle

9. Turn off electrical equipment rather than use 'standby' mode

10. Eat food which is locally-grown or in season

11. Use car-sharing or car-pooling schemes

12. Buy products with less packaging 


\section{Public-sphere mitigation behavior}

1. Sign a petition in support of protecting the environment

2. Join or renew membership of an environmental group

3. Join public demonstrations or protests supporting environmental protection

4. Write a letter to a Member of Parliament or government official to support environmental protection

5. Donate money to an environmental group

6. Read a newsletter, magazine, or other publication written by an environmental group

7. Vote in favor of a political candidate because he or she was strongly in favor of environmental protection

8. Write to a newspaper in support of protecting the environment

9. Boycott companies that are not environmentally friendly

10. Volunteer to help an environmental group or event

11. Post pro-environmental messages or links on social media (for example, Facebook, Twitter, etc.)

12. Speak in favor of pro-environmental policies in conversations with your friends or family

\section{Support for national indicators}

1. Economic output

2. Life-expectancies (i.e., how long people in the nation live)

3. Life-satisfaction (i.e., how satisfied with their life people in the nation are)

4. Environmental impact (i.e., how much benefit, relative to destruction, people in the nation cause to the environment)

\section{Perceived co-benefits of climate change mitigation}

Societal development

1. Do you think the economy will be more or less developed, compared to today?

2. Do you think the average education level of people will be higher or lower, compared to today?

3. Do you think volunteering will be more or less common, compared to today?

4. Do you think there will be faster or slower scientific progress, compared to today?

5. Do you think there will be more or less community groups, compared to today?

Societal dysfunction

1. Do you think there will be more or less violent crimes, compared to today?

2. Do you think more or less people will be in poverty, compared to today?

3. Do you think diseases will be more or less prevalent, compared to today?

4. Do you think pollution will be more or less serious, compared to today?

5. Do you think there will be more or less thefts, compared to today?

6. Do you think unemployment level will be higher or lower, compared to today?

Cultural preservation

1. Do you think preservation of cultures will be better or worse, compared to today?

2. Do you think there will be more or less authentic cultural practices, compared to today?

3. Do you think traditional cultural values will be more or less preserved, compared to today? 
4. Do you think protection of cultural heritage will be better or worse, compared to today?

5. Do you think the condition of indigenous cultures will be better or worse, compared to today?

6. Do you think level of cultural diversity will be higher or lower, compared to today? 


\section{S2. Measures in Study 2}

Perceived Cultural Impacts of Climate Change Scale

Please refer to Table 1 in the main text.

Open-ended question about the cultural impacts of climate change

When you were answering the questions in the previous page (about the impacts of climate change on cultures), what kinds of impacts and what kinds of cultures were you thinking about? Please explain in detail below.

Private-sphere mitigation behavior

The measure in Study 1 was used.

\section{Climate activism}

1. Sign a petition about climate change, either online or in person

2. Vote for a candidate for public office because of their position on climate change

3. Publicly display a t-shirt, bumper sticker, button, wrist band, or sign about climate change

4. Attend a public meeting or presentation about climate change

5. Attend a neighborhood meeting to discuss climate change and actions people can take

6. Donate money to an organization working on climate change

7. Share information about climate change on social media (e.g., Facebook, Twitter, Instagram, YouTube)

8. Volunteer your time to an organization working on climate change

9. Meet with an elected official or their staff about climate change

10. Write letters, email, or phone government officials about climate change

11. Support an organization engaging in non-violent civil disobedience (e.g., sit-ins, blockades, or trespassing) against corporate or government activities that make climate change worse

12. Attend a political rally, speech, or organized protest about climate change

13. Personally engage in non-violent civil disobedience (e.g., sit-ins, blockades, or trespassing) against corporate or government activities that make climate change worse

Support for climate policy

1. Require fossil fuel companies to pay a fee on carbon pollution, and distribute the money collected to all U.S. citizens, in equal amounts, through monthly dividend checks

2. Require fossil fuel companies to pay a carbon tax and use the money to reduce other taxes (such as income tax) by an equal amount

3. Fund more research into renewable energy sources, such as solar and wind power

4. Generate renewable energy (solar and wind) on public land in the U.S.

5. Provide tax rebates for people who purchase energy-efficient vehicles or solar panels

6. Regulate carbon dioxide (the primary greenhouse gas) as a pollutant

7. Require electric utilities to produce at least $20 \%$ of their electricity from wind, solar, or other renewable energy sources, even if it costs the average household an extra \$100 a year 
1. Expand offshore drilling for oil and natural gas off the U.S. coast

2. Drill for and mine fossil fuels (coal, oil, and natural gas) on public land in the U.S.

3. Drill for oil in the Arctic National Wildlife Refuge

Support for the U.S. participation in the Paris Agreement

1. In 2015, the United States signed an international agreement in Paris with 196 other countries to limit the pollution that causes climate change. Do you support or oppose the U.S.'s participation in the Paris Agreement?

2. The U.S. is the world's second largest emitter of the pollution that causes climate change. President Trump recently announced his decision to pull the U.S. out of the Paris Agreement, but all other countries have responded that they remain committed to the agreement. Do you support or oppose President Trump's decision to pull out of the Paris Agreement?

Importance of climate change in voting decisions

1. In this year, there will be an election to choose a U.S. president. As of today, how important will the issue of climate change be to you when you decide who you will vote for in the 2020 Presidential election?

\section{Climate change opinions}

1. Assuming climate change is happening, do you think it is...?

Caused mostly by human activities

Caused mostly by natural changes in the environment

Neither because climate change isn't happening

Other (please specify)

2. Which comes closest to your own view?

Most scientists think climate change is happening.

There is a lot of disagreement among scientists about whether or not climate change is happening.

Most scientists think climate change is not happening.

Don't know enough to say.

3. How much do you think climate change will harm you personally?

4. How much do you think climate change will harm people in the United States? 


\section{S3. Analysis of the Open-Ended Responses in Study 2}

Participants were asked an open-ended question to explain in detail what kinds of impacts and cultures they had been thinking about when completing the Perceived Cultural Impacts of Climate Change Scale. To probe further into our participants' understanding of the cultural impacts, we explored their responses to this open-ended question with a qualitative analysis.

The participants' responses varied hugely in terms of length, ranging from 1 word to 581 words $(M=40.88$ and $S D=37.03)$. To analyze these responses, we followed the inductive and semantic approach of thematic analysis (Braun \& Clarke, 2006). Our goal was to identify patterned meanings from the explicit contents of the responses.

We made use of researcher triangulation based on the recommendation by Nowell et al. (2017). Specifically, the first author and two undergraduate students with social science research training performed the analysis as a team. Following the steps suggested by Braun and Clarke (2006), each team member independently familiarized themselves with the responses, generated codes, and searched for themes that can organize the codes. The team members then reviewed their codes and themes together. Through three rounds of discussions, four themes were vetted in the end. These themes were then defined and named. Following the recommendations by Braun et al. (The University of Auckland, n.d.), we did not count percentages or frequencies of the codes and themes identified, as frequency does not determine the value of a code or theme. Table S1 lists the four themes and the specific codes underneath.

The first theme was environmental changes responsible for the cultural impacts. When describing examples of the cultural impacts of climate change, our participants named a huge variety of environmental changes that they perceived to be responsible for the impacts.

The second theme was types of people affected by the cultural impacts. A wide range of communities or populations were identified in the examples provided by the participants.

The third theme was regions suffering from the cultural impacts. Under this theme, we observed that our participants collectively referred to all continents of the world in their examples.

The fourth theme was aspects of culture impacted. Our participants articulated the impacts of climate change on human cultures in various ways.

Altogether, this analysis suggests that, collectively speaking, our participants showed concrete understanding of the cultural impacts of climate change. This observation corroborates the high average level of awareness as reflected by their scores on the Perceived Cultural Impacts of Climate Change Scale. Having said that, we argue that we should not lose sight of the variations between participants. As noted, some participants offered only a very brief response to the open-ended question, while some gave a very elaborate answer with multiple examples named. As also observed with the scores on the Perceived Cultural Impacts of Climate Change Scale, there are apparently substantial individual differences in terms of understanding of the cultural impacts of climate change. 
Table S1. Themes and codes identified in the participants' open-ended responses in Study 2.

\begin{tabular}{|c|c|}
\hline Theme & Code \\
\hline $\begin{array}{l}\text { Environmental changes } \\
\text { responsible for the cultural } \\
\text { impacts }\end{array}$ & $\begin{array}{ll}\text { - } & \text { rising sea levels } \\
\text { - } & \text { ocean warming } \\
\text { - } & \text { ocean acidification } \\
\text { - } & \text { coastal/shore erosion } \\
\text { - } & \text { tsunami } \\
\text { - } & \text { tropical storm/hurricane/cyclone/typhoon } \\
\text { - } & \text { abnormal snow pattern } \\
\text { - } & \text { blizzards } \\
\text { - } & \text { melting snow/glacier } \\
\text { - } & \text { avalanche } \\
\text { - } & \text { abnormal rainfalls } \\
\text { - droughts } \\
\text { - } \text { extreme temperatures } \\
\text { - heatwaves } \\
\text { - } \text { abnormal seasons } \\
\text { - } \text { fire } \\
\text { - } \text { dysfunctional ecosystem } \\
\text { - decreased biodiversity } \\
\text { - disrupted plant growth } \\
\text { - } \text { ozone layer depletion } \\
\text { - desertification } \\
\text { - mudslides }\end{array}$ \\
\hline $\begin{array}{l}\text { Types of people affected by the } \\
\text { cultural impacts }\end{array}$ & $\begin{array}{ll}\text { - } & \text { indigenous peoples } \\
\text { - } & \text { sparsely populated communities } \\
\text { - } & \text { populations in highly populated areas } \\
\text { - } & \text { coastal communities } \\
\text { - } & \text { communities in low-lying areas } \\
\text { - } & \text { islandic communities/archipelago countries } \\
\text { - landlocked communities } \\
\text { - } \text { farmers } \\
\text { - hunters } \\
\text { - } \text { fishermen } \\
\text { - nomadic communities } \\
\text { - } \text { populations in warm/hot climate } \\
\text { - } \text { people living under cold climate } \\
\text { - } \text { people living in rainforests } \\
\text { - the West } \\
\text { - } \text { de East }\end{array}$ \\
\hline
\end{tabular}




\begin{tabular}{|c|c|}
\hline & $\begin{array}{ll}\text { - } & \text { developing countries } \\
\text { - } & \text { Third World countries } \\
\text { - } & \text { poor communities } \\
\text { - } & \text { immigrants } \\
\text { - } & \text { small/ marginalized communities } \\
\text { - } & \text { children } \\
\text { - } & \text { elderly } \\
\text { - } & \text { Islamic populations } \\
\text { - } & \text { desert communities } \\
\text { - } & \text { oil-producing communities } \\
\text { - } & \text { future generations }\end{array}$ \\
\hline $\begin{array}{l}\text { Regions suffering from the } \\
\text { cultural impacts }\end{array}$ & $\begin{array}{l}\text { Pacific Ocean and Oceania } \\
\text { Tonga } \\
\text { Samoa } \\
\text { Micronesia } \\
\text { Marshall Islands } \\
\text { Australia } \\
\text { New Zealand } \\
\text { Kiribati } \\
\text { Papua New Guinea } \\
\text { Indian Ocean } \\
\text { Polynesia } \\
\text { Africa } \\
\text { Senegal } \\
\text { Seychelles } \\
\text { Egypt } \\
\text { Malawi } \\
\text { Madagascar } \\
\text { Tangier } \\
\text { Europe } \\
\text { The Netherlands } \\
\text { Ireland } \\
\text { Finland } \\
\text { Sweden } \\
\text { Norway } \\
\text { Scandinavia } \\
\text { Greenland } \\
\text { Iceland } \\
\text { Poland } \\
\text { Venice } \\
\text { Russia } \\
\text { North America } \\
\text { Bahama } \\
\text { Canada } \\
\text { Greenland } \\
\text { United States (Alaska/South Carolina/Charleston } \\
\text { /Manhattan/Boston/Virginia/Texas/California/Puerto }\end{array}$ \\
\hline
\end{tabular}




\begin{tabular}{|c|c|}
\hline & $\begin{array}{l}\text { Rico/New York/Florida/Louisiana/New Orleans/ } \\
\text { Newark/Hawaii) } \\
\text { - South America } \\
\text { Amazon } \\
\text { Brazil } \\
\text { Mexico } \\
\text { - Asia } \\
\text { Japan } \\
\text { Hong Kong } \\
\text { Thailand } \\
\text { Borneo } \\
\text { Sri Lanka } \\
\text { Siberia } \\
\text { Haiti } \\
\text { Philippines } \\
\text { India } \\
\text { Pakistan } \\
\text { Vietnam } \\
\text { Bangladesh } \\
\text { Indonesia } \\
\text { Bali } \\
\text { Maldives } \\
\text { Turkey } \\
\text { Syria } \\
\text { Solomon Island } \\
\text { Sentinel island } \\
\text { Middle East } \\
\text { Indian Ocean } \\
\text { Antarctica } \\
\text { South Pole } \\
\text { Arctic Circle } \\
\text { North Pole }\end{array}$ \\
\hline Aspects of culture impacted & $\begin{array}{ll}\text { - } & \text { cultural extinction } \\
\text { - } & \text { cultural marginalization } \\
\text { - } & \text { decreased cultural diversity } \\
\text { - } & \text { cultural mixing/blending } \\
\text { - } & \text { influx of foreign culture } \\
\text { - } & \text { loss of cultural identity } \\
\text { - } & \text { loss of cultural heritage } \\
\text { - } & \text { loss of tradition } \\
\text { - } & \text { loss of values } \\
\text { - } & \text { loss of language } \\
\text { - } & \text { loss of homelands } \\
\text { - } & \text { change in lifestyles } \\
\text { - } & \text { disruption of subsistence activities } \\
\text { - } & \text { disruption of other economic activities (e.g., tourism) }\end{array}$ \\
\hline
\end{tabular}


- short of supply of basic resources (e.g., food, water)

- disruption to family structure

- disruption to demographic structure

- threats to health and life

- intergroup or intercultural conflicts

- reduced resilience against climate change 


\section{S4. Exploratory Analysis in Study 2}

We explored to what extent perceived cultural impacts and political orientation interacted with each other in predicting climate change engagement.

For each of the outcome variables, we added the interaction between perceived cultural impacts and political ideology (higher scores $=$ more liberal) into the regression model. This interaction was not significant for private-sphere mitigation behavior $(p=.547)$, climate activism $(p=.630)$, and importance of climate change in voting decisions ( $\mathrm{p}=.746)$. Nevertheless, it was negative and significant for support for climate policy $(b=-.07$, SE $=.01, p<.001)$ and support for the U.S. participation in the Paris Agreement $(b=-.11$, SE $=.02, p<.001)$. Also, it was positive and significant for support for fossil fuel industry ( $b$ $=.05$, SE $=.02, p=.023$ ). These effects imply that the association between political ideology and these outcome variables was weaker among individuals whose awareness of the cultural impacts of climate change was high. Put it differently, perceived cultural impacts seemed to be more motivating for climate action among conservative individuals than liberal individuals. Figures S1 to S3 visualize this pattern.

We also replicated the above analysis with the Republican dummy-coded variable $(1=$ Republican, with Democrat as the reference category) replacing political ideology. The pattern of results was essentially the same. This interaction was not significant for privatesphere mitigation behavior ( $p=.107)$, climate activism $(p=.576)$, and importance of climate change in voting decisions $(p=.102)$. Nevertheless, it was positive and significant for support for climate policy $(b=.16, \mathrm{SE}=.04, p<.001)$ and support for the U.S. participation in the Paris Agreement $(b=26, \mathrm{SE}=.04, p<.001)$. Also, it was negative and marginally significant for support for fossil fuel industry $(b=-.12$, SE $=.06, p=.059)$. These significant effects imply that the divide between Republicans and Democrats in terms of their support for climate policy, support for fossil fuel industry, and support for the U.S. participation in the Paris Agreement was weaker among those whose awareness of cultural impacts of climate change was high. Put it differently, perceived cultural impacts of climate change seemed to be more strongly associated with climate policy support among Republicans than Democrats. 
Figure S1. Interaction between perceived cultural impacts and political ideology in Study 2 (support for climate policy).
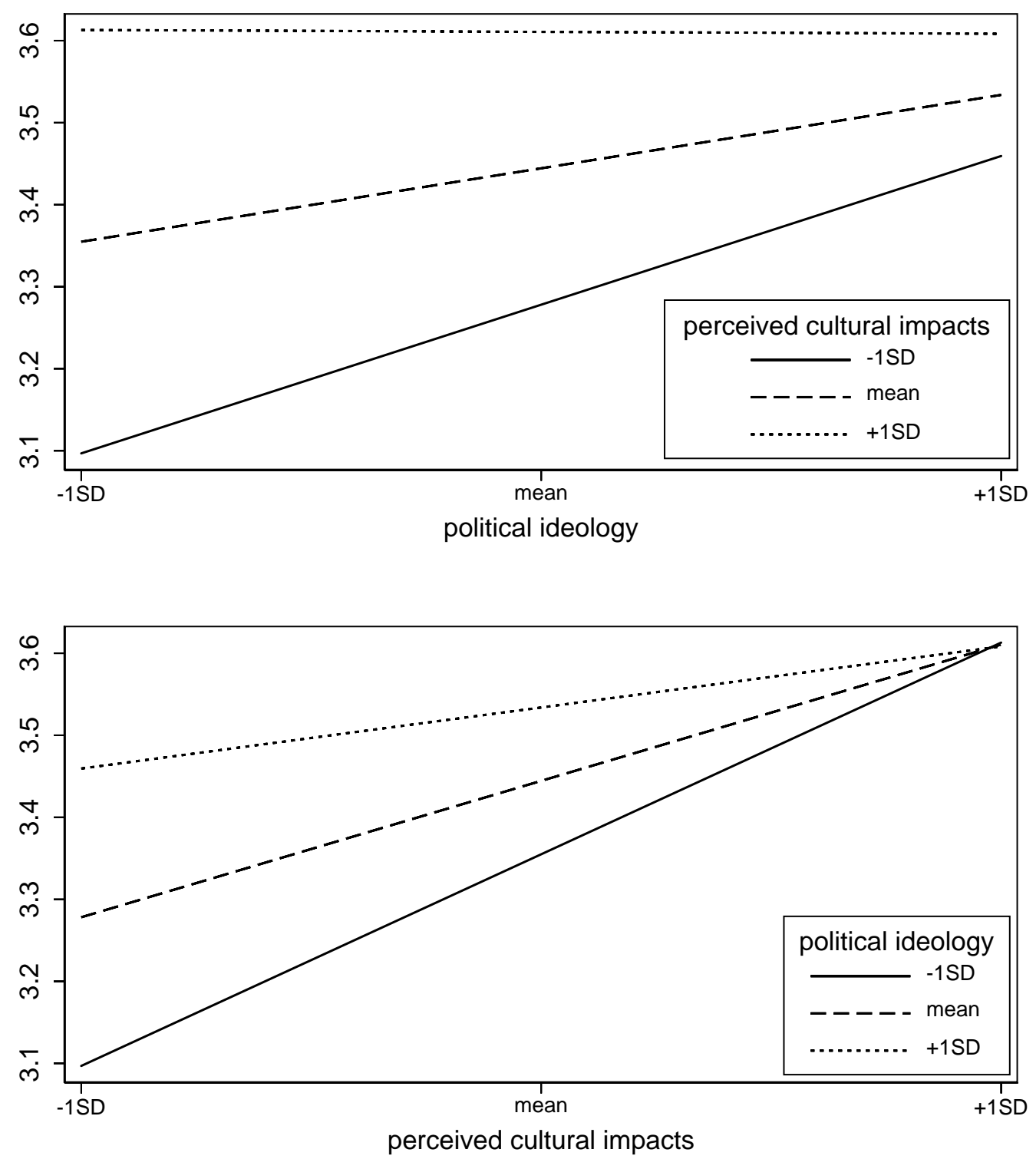
Figure S2. Interaction between perceived cultural impacts and political ideology in Study 2 (support for fossil fuel industry).
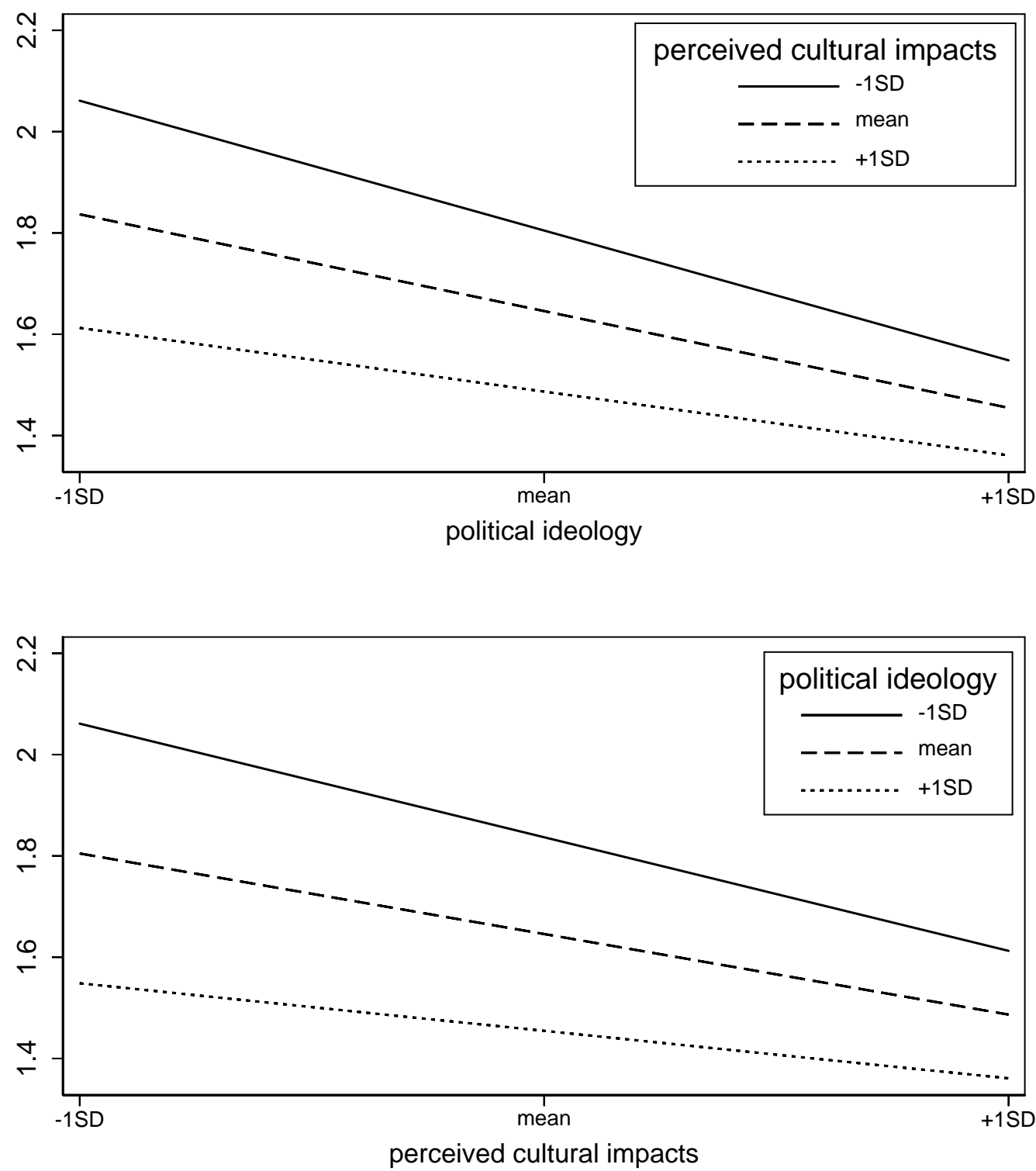
Figure S3. Interaction between perceived cultural impacts and political ideology in Study 2 (support for the U.S. participation in the Paris Agreement).
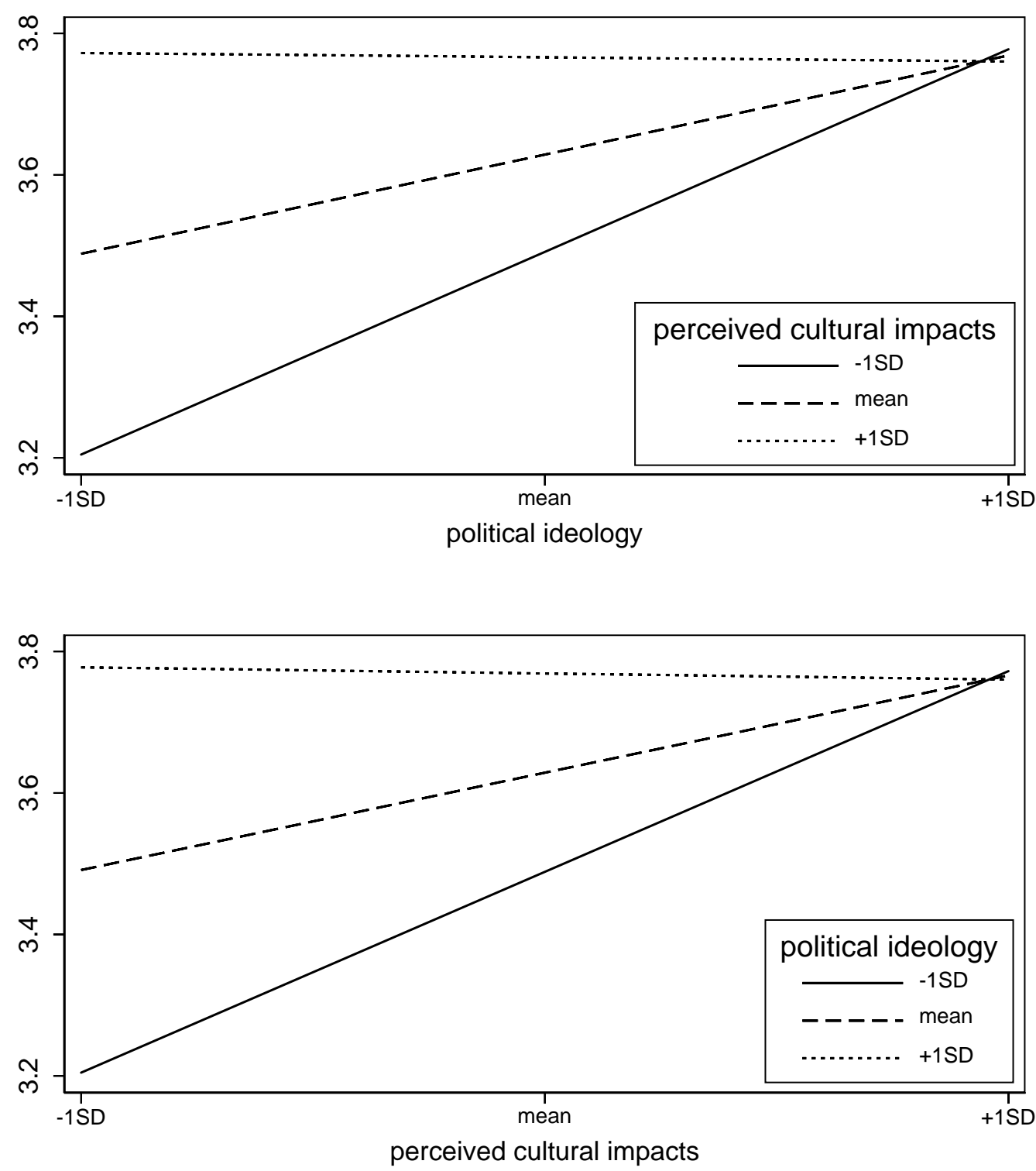